\title{
The Community Mobilization for Preventive Action (COMPACT) project in Zambia: A midline evaluation
}

\author{
Waimar Tun \\ Population Council \\ Chabu Kangale \\ Population Council \\ Scott Geibel \\ Population Council \\ Meredith Sheehy \\ Population Council
}

Ray Handema

See next page for additional authors

Follow this and additional works at: https://knowledgecommons.popcouncil.org/departments_sbsr-hiv

Part of the Community-Based Research Commons, Community Health and Preventive Medicine Commons, Health Policy Commons, Immune System Diseases Commons, Public Health Education and Promotion Commons, and the Virus Diseases Commons How does access to this work benefit you? Let us know!

\section{Recommended Citation}

Tun, Waimar, Chabu Kangale, Scott Geibel, Meredith Sheehy, Ray Handema, and Mwaka Monze. 2013. "The Community Mobilization for Preventive Action (COMPACT) project in Zambia: A midline evaluation." Lusaka: Population Council. 
Authors

Waimar Tun, Chabu Kangale, Scott Geibel, Meredith Sheehy, Ray Handema, and Mwaka Monze

This report is available at Knowledge Commons: https://knowledgecommons.popcouncil.org/departments_sbsr-hiv/ 


\section{THE COMMUNITY MOBILIZATION FOR PREVENTIVE ACTION (COMPACT) PROJECT IN ZAMBIA: A MIDLINE EVALUATION}

Midline

Evaluation

Report
USAID USAID USAID

(घ)

USAID USAID

(3)

USAID USAID USAID

()ㅜㅇ

USAID USAID

하 훙

USAID USAID USAID

(3)

USAID USAID

(5) USAID USAID USAID (:) USAID USAID USAID USAID USAID
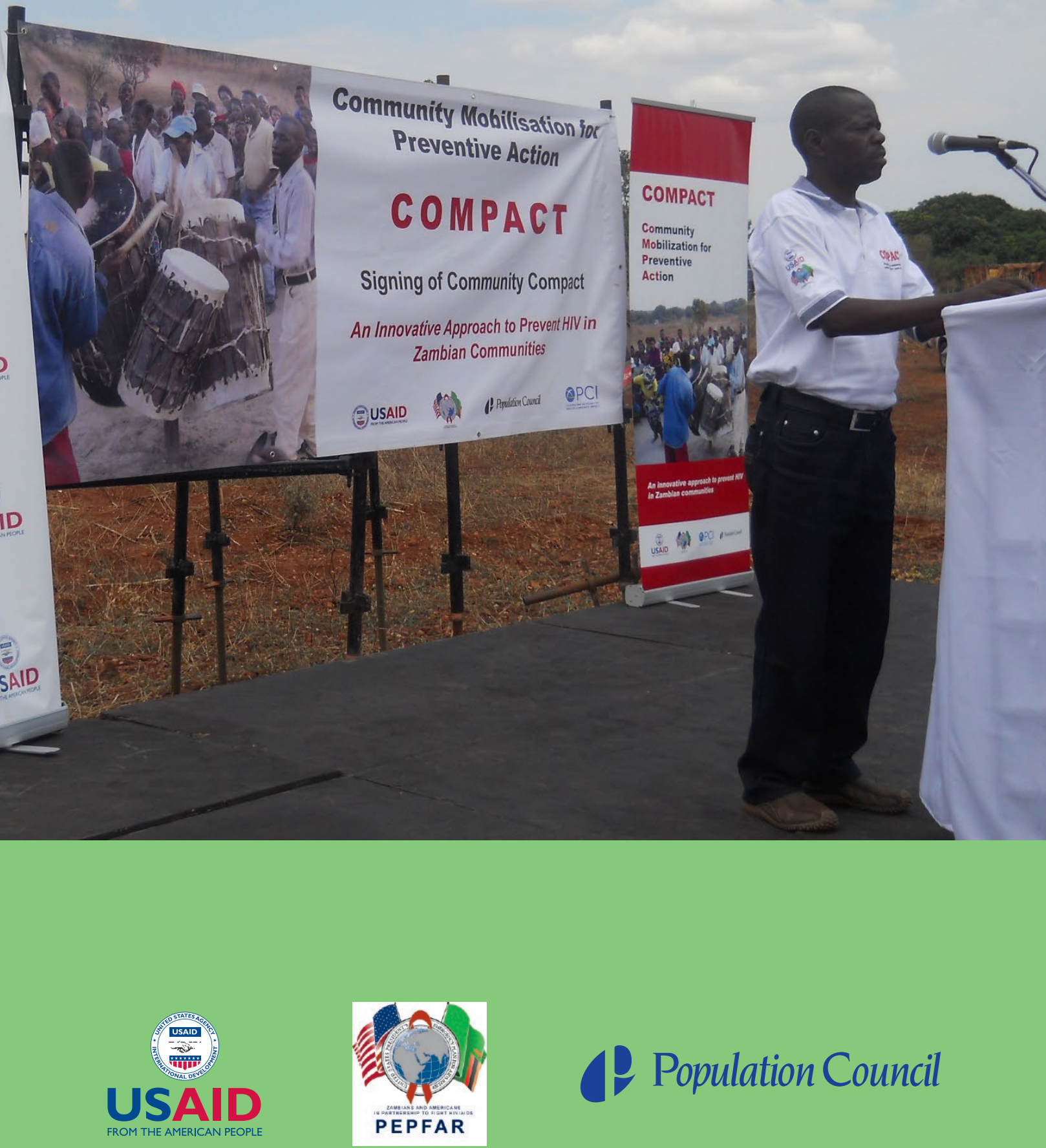

12 Population Council 



\section{THE COMMUNITY MOBILIZATION FOR PREVENTIVE ACTION (COMPACT) PROJECT IN ZAMBIA: A MIDLINE EVALUATION}

\section{Principal Investigators}

Waimar Tun ${ }^{1}$ and Chabu Kangale ${ }^{2}$

Co-Investigators

Scott Geibel ${ }^{1}$ and Meredith Sheehy ${ }^{3}$

For Sero-survey only

Ray Handema ${ }^{4}$ and Mwaka Monze ${ }^{5}$

${ }^{1}$ Population Council, Washington, DC, USA

${ }^{2}$ Population Council, Lusaka, Zambia

${ }^{3}$ Population Council, New York, USA

${ }^{4}$ Tropical Diseases Research Center (TDRC), Ndola, Zambia

${ }^{5}$ Virology Laboratory, Lusaka, Zambia
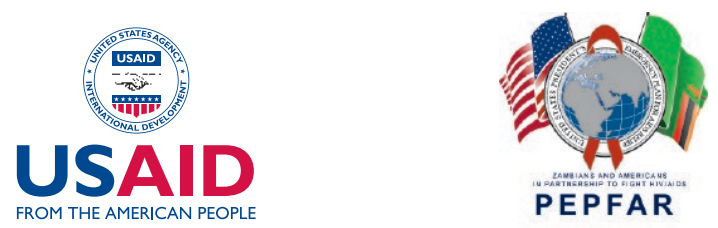

(2) Population Council 


\section{ACKNOWLEDGEMENTS}

The Community Mobilization for Preventive Action (COMPACT) project acknowledges the efforts of all those who contributed to the successful conduct of the midline survey and report. In particular, the Tropical Diseases Research Centre (TDRC) and the Virology Laboratory of the University Teaching Hospital, in particular Dr. Ray Handema and Dr. Mwaka Monze, respectively, for ensuring successful specimen collection, HIV testing, and storage of the samples. COMPACT also acknowledges the efforts of Kintu Kaluswika for managing the data collection exercise, and Dr. Julie Pulerwitz for her critical review of the report.

We are also grateful to Dr. Kakungu Simpungwe, District Health Officer for Ndola District, and Dr. Charles Msiska, District Health Officer for Chongwe District, for their continued support during the data collection process. We thank all the respondents who gave their time to participate in the study.

In addition, we gratefully acknowledge the United States Agency for International Development (USAID) for supporting the project.

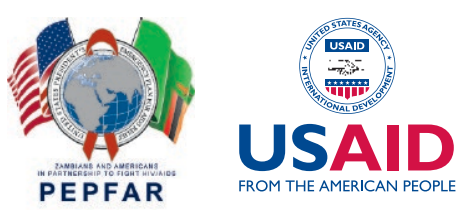

This report is made possible by the generous support of the American people through USAID. The contents of this are the sole responsibility of the COMPACT Project and Population Council and do not necessarily reflect the views of USAID or the United States Government.

\section{(2) Population Council}

The Population Council confronts critical health and development issues-from stopping the spread of HIV to improving reproductive health and ensuring that young people lead full and productive lives. Through biomedical, social science and public health research in about 50 countries, the Council works with our partners to deliver solutions that lead to more effective policies, programs, and technologies to improve lives worldwide. Established in 1952 and headquartered in New York, the Council is a nongovernmental, nonprofit organization with an international board of trustees.

www.popcouncil.org

(C) 2013 The Population Council, Inc.

Front cover photo: CPopulation Council

Suggested citation: Tun, Waimar, Chabu Kangale, Scott Geibel, Meredith Sheehy, Ray Handema, and Mwaka Monze. 2013. "The Community Mobilization for Preventive Action (COMPACT) project in Zambia: A midline evaluation," Midline Evaluation Report. Lusaka: Population Council.

Any part of this publication may be photocopied without permission from the publisher provided that copies are distributed without charge and that full source citation is provided. The Population Council would appreciate receiving a copy of any materials in which the text is used. 


\section{TABLE OF CONTENTS}

Acronyms

Executive Summary 1

$\begin{array}{ll}\text { Background } & 3\end{array}$

Methodology 5

Study Sample and Procedures

Intervention Description $\quad 6$

Analysis 6

Results $\quad 7$

$\begin{array}{ll}\text { Sample Characteristics } & 7\end{array}$

Exposure to COMPACT Activities $\quad 7$

Changes in Key Outcomes $\quad 7$

$\begin{array}{lr}\text { Conclusion and Next Steps } & 18\end{array}$

$\begin{array}{ll}\text { References } & 21\end{array}$

$\begin{array}{ll}\text { Appendices } & 22\end{array}$ 


\section{ACRONYMS}

$\begin{array}{ll}\text { CBO } & \text { Community-based Organization } \\ \text { CCDC } & \text { Community Compact Development Committee } \\ \text { COMPACT } & \text { Community Mobilization for Preventive Action } \\ \text { CSO } & \text { Central Statistical Office } \\ \text { MOT } & \text { Modes of Transmission } \\ \text { PCI } & \text { Project Concern International } \\ \text { PDA } & \text { Personal Digital Assistant } \\ \text { PLHIV } & \text { People Living with HIV } \\ \text { SEA } & \text { Standard Enumeration Area }\end{array}$




\section{EXECUTIVE SUMMARY}

Community mobilization strategies are increasingly used in HIV prevention programs. The Population Council and its partner, Project Concern International (PCl), are implementing the Community Mobilization for Preventive Action (COMPACT) project in Zambia. The program works with communities to develop "compacts" through a participatory, community-led process, and assists them in working toward reaching HIV-related "benchmarks," intended to result in a reduction in HIV-related risk behaviors and harmful norms and ultimately contribute over time to the reduction of HIV incidence. Communities receive monetary rewards upon achieving each benchmark, and they determine how best to use the funds. COMPACT interventions address HIV testing, gender-based violence, inequitable gender norms, sexual risk behaviors, alcohol abuse, contraceptive use, PLHIV support, and economic empowerment.

We conducted a mid-term evaluation in four of six COMPACT communities. The evaluation used a cohort study design and recruited male and female participants through a community-based household survey with HIV testing. A total of 1,921 participants completed both the baseline and midline survey. Analysis was stratified by sex, community, and exposure status. McNemar's test for repeated measures on two related samples was used to test the significance of changes within groups from baseline to midline.

Overall, results indicated significant improvements with several indicators that were associated with exposure to COMPACT. There was a decrease in levels of males having non-regular sex partnerships among the exposed group (37 percent to 18 percent) while the level remained steady at approximately 30 percent among the unexposed group. Additionally, exposure effect was observed with regard to equitable gender attitudes and alcohol abuse problems. Significantly greater improvements were seen in the exposed versus unexposed groups in equitable gender attitudes among females in Chinyunyu (Exposed: 62 percent to 81 percent; Unexposed: 69 percent to 74 percent) and Chongwe (Exposed: 74 percent to 87 percent; Unexposed: 76 percent to 80 percent), and alcohol abuse problems among males in Chinyunyu (Exposed: 29 percent to 13 percent; Unexposed: 27 percent to 16 percent).

Although there were no differences by exposure status, there were significant increases in all communities from baseline to midline in HIV knowledge (from an average of 50 percent to 65 percent), HIV testing (from an average of 40 percent to 80 percent in males and 70 percent to 90 percent in females), contraceptive use among sexually active adolescent girls (from 9-11 percent to 26-32 percent), and reductions in support of rape myths (from 54-59 percent to 39-47 percent in males; from 50 percent to 34 percent in females), and multiple sex partnerships (from 15 percent to 10 percent in males; from 7 percent to 2 percent in females).

The HIV seroincidence rate was 2.6/100 person-years (PY) (95\% Cl: 1.1-5.7) in Kaniki and 2.3/100 PY (95\% Cl: 1.0-5.5) in Kawama. Seroconversion was significantly associated with alcohol abuse problem; those who had an alcohol abuse problem were seven times more likely to seroconvert compared to those who did not have a problem. Additionally, we found that participation in income generation programs and Gender Action Groups appear to have a protective association.

Despite these positive changes, there are some areas in which there were no statistically significant improvements. There was no change in the proportion having an unintended pregnancy among adolescent girls (approximately three-quarters of girls reporting the last pregnancy was 
unintended). Lastly, there was an increase in women's reporting of sexual violence (from 5 percent at baseline to 13-16 percent at midline). However, the increase may be due to greater awareness that physical and sexual violence are not acceptable regardless of the circumstances, and that they are in fact considered abuse as opposed to an acceptable norm. COMPACT will need to focus especially in these areas as it transitions into its last year of the program. Additionally, HIV prevention programs in Zambia must incorporate alcohol risk reduction activities. Further, lessons learned from income generation programs and programs addressing harmful gender norms should be used to strengthen other HIV prevention programs. 
An estimated 14 percent of the Zambian population is living with HIV (Central Statistical Office 2007). The epidemic disproportionately affects women and urban residents (16 and 20 percent, respectively), although all segments of society have been impacted. While overall HIV prevalence appears to be decreasing since 2001, modeled incidence rates from the Modes of Transmission (MOT) study suggest that 1.6 percent of the population is newly infected each year (Zambia National HIV/AIDS/STI/TB Council 2009).

The Zambia National HIV/AIDS/STI/TB Council (NAC) identifies six core drivers of the epidemic in Zambia: (1) multiple and concurrent sexual partnerships; (2) low and inconsistent condom use; (3) low levels of male circumcision; (4) mobility and labor migration; (5) high-risk behaviors among sex workers and in male-to-male relationships; and (6) vertical transmission from mother to child. In addition, NAC also identifies a set of structural, community-level drivers that have largely remained unaddressed by HIV programs and research and urges programs to address these issues that underpin continued incidence. They include alcohol use, gender inequality, harmful gender norms, sexual and intimate partner violence, transactional sex, and taboos and social barriers regarding communication among couples.

The Population Council and its partner, Project Concern International (PCl), are implementing a "community compact" intervention in four Zambian communities. COMPACT builds upon existing interventions, structures, and partnerships to further promote HIV prevention at the community-level. COMPACT works directly with communities to design and implement the community compacts. COMPACT develops compacts through a participatory, community-led process, and assists them in working toward reaching HIV-related "benchmarks," intended to result in a reduction in HIV-related risk behaviors and harmful norms and ultimately contribute over time to the reduction of HIV incidence. A cornerstone of the compact approach is to work with existing community structures to form a Community Compact Development Committee (CCDC), comprising community leaders and other stakeholders, to manage the compact. There are four core components to the compacts. The first component is the multitude of evidence-based interventions that address the key drivers of the epidemic such as risky sexual behaviors, alcohol use, gender-based violence, and harmful male norms. The second core component is the group of implementing community-based organizations (CBOs) that are identified to implement the interventions. The next component is the set of benchmarks that comprise activity-specific targets that must be met or exceeded to qualify for a reward. Benchmarks help to ensure that rewards are provided with necessary frequency to encourage excitement and engagement. Four benchmarks are linked to process (e.g., Safe Spaces groups formed with 50 members per group), intermediate measures (e.g., 1,800 adults reached through Safe Love Club activities), and final results of project implementation (e.g., 725 adults test and know their HIV status). A final benchmark is the ultimate behavioral outcome (e.g., 50 percent reduction in alcohol abuse, 50 percent reduction in multiple partnerships). The last core component is the reward; the CCDC decides on appropriate rewards to give to CBOs, which are given in a highly visible manner upon achieving each benchmark. Rewards are community goods that are intended to further the goals of each intervention; they do not benefit individuals or private interests. For example, upon achieving the first benchmark, the Mushili community received a fridge for storing vaccines and reagents and a TV and DVD player to show sexual and reproductive health messages at the Mushili Clinic; the Chongwe community received bedding, chairs, and benches for the Chongwe District Hospital; and the Chinyunyu community received goats and day old chicks for income generation activities for vulnerable women and youth. 
To assess changes in knowledge, attitudes, and practices as a result of these interventions, cohorts of people living in the COMPACT communities were recruited and interviewed in 2011, and re-interviewed in 2012/2013. Presented here are findings related to the impact of the COMPACT interventions. 


\section{METHODOLOGY}

\section{Study Sample and Procedures}

The evaluation was conducted in two rural communities (Chinyunyu and Kaniki) and two peri-urban communities (Chongwe and Kawama) where COMPACT interventions were implemented. Chinyunyu and Chongwe are located in Lusaka province, and Kaniki and Kawama are in the Copperbelt province. These communities were selected in consultation with the Ministry of Health through the District Health Offices in Chongwe and Ndola districts based on criteria of rural peri-urban balance, high prevalence of HIV, and willingness of the community to implement a community-driven and incentive-based project with an evaluation component.

This evaluation was a cohort study of participants recruited through a community-based household survey. Eligibility criteria at baseline included: i) being female aged 15 to 49 years or males aged 15 to 59 years; ii) being permanent residents of a household or having spent the previous night in the household; and iii) having no plans to migrate from the current residence for the next three years. A cluster sampling technique was used so that interviews could be carried out in a smaller number of geographical locations known as standard enumeration areas (SEAs). ${ }^{1}$ Ten SEAs were randomly selected from each ward. Household residents were then randomly selected in each SEA. The target sample size was allocated to the four communities in proportion to the population size of each community based on household enumeration prior to data collection. A total of 3,162 men and women were interviewed at baseline (October to December 2011); of those, 2,010 were interviewed at midline (November 2012 to May 2013). A total of 89 respondents who had discrepancies in their reported age by more than 10 years and sex between baseline and midline were dropped. This analysis is based on the 1,921 (62.5 percent) who completed both baseline and midline surveys (after dropping the 89). Some of the reasons for the loss-tofollow-up included: migration, failure to locate the same person from baseline, and seasonal labor (i.e., those in rural communities of Kaniki and Chinyunyu migrated for farming in other villages).

The study elicited information on sociodemographic characteristics, HIV knowledge, gender-based violence, family planning, attitudes toward PLHIV, sexual abuse, couple communication, self-risk perception, HIV counseling and testing, alcohol use, sexual behaviors, gender norms, and exposure to COMPACT activities. Interviews were conducted with personal digital assistants (PDAs) at the participants' homes, in Bemba (Copperbelt) or Nyanja (Lusaka).

All participants were asked to provide a venous blood sample for anonymous HIV testing (i.e., respondents do not receive their test results) at baseline and follow-up rounds of data collection. In order to protect participant's confidentiality, regardless of the result of the baseline HIV test result, all participants at midline were asked to provide a sample for HIV testing. Each specimen was screened with the Determine ${ }^{\circledR}$ HIV-1/2 Test. Specimens testing positive on this test were confirmed on the Uni-GoldTM HIV Test. Specimens with discrepant results between the two tests were subjected to a SD Bioline HIV-1/2 3.0 Test, which was used as the tie breaker.

We report HIV incidence for Kaniki and Kawama only. Kaniki represents a rural community while Kawama is a peri-urban community. We could not accurately determine incidence in Chongwe

${ }^{1}$ A SEA is the lowest geographic cluster used by the Central Statistical Office (CSO) of the Government of Zambia in demographic surveys. An SEA is a convenient geographical area with an average size of 130 households or 600 people. For each SEA there is a map indicating its geographical limits using main landmarks in the community. 
and Chinyunyu since some of the test results from baseline and midline may have been incorrectly linked.

\section{Intervention Description}

Working with the CCDC, the COMPACT team conducted community self-assessments to determine the key drivers of HIV in each community and prioritized the key drivers in each community (e.g., multiple sexual partnerships, alcohol abuse, vulnerability of girls, gender-based violence, access to condoms, and HIV-related stigma and discrimination). Several interventions were developed or adapted in response to each of the key drivers relevant to each community. COMPACT interventions include: i) Safe Spaces for Girls, a program in which 12 to 15 year old in- and out-of-school girls learn about life and survival skills and participate in income generation activities; ii) Gender Action Groups, which are discussion group meetings related to gender-based violence and gender inequality; iii) Safe Love Clubs, discussion group meetings related to safer sex and health relationships; iv) Income generation activities, whereby participants learn how to create income (e.g., through rearing chickens, gardening, photocopying, and internet services) as well as learn life skills and HIV prevention; v) PLHIV support groups which serves as a resource for PLHIV to live positively; and vi) alcohol abuse prevention programs which conducted alcohol harm reduction educational sessions and distributed educational materials. There were also more widely implemented community-based activities such as outreach referrals for HIV testing and stigma reduction campaigns.

\section{Analysis}

Findings are stratified by community, sex, and exposure to COMPACT. A participant was considered to have been exposed to COMPACT if he/she participated in at least one of the following COMPACT activities in the last 12 months: i) Safe Spaces for girls; ii) Safe Love Clubs; iii) Income generation activities; iv) PLHIV support groups; v) Gender Action Groups; or vi) Alcohol abuse prevention education. For each exposed and unexposed group, McNemar's test for repeated measures on two related samples was used to test the significance of changes within groups from baseline to midline. To examine potential biases from loss to follow-up, we compared key baseline characteristics of those who completed both baseline and midline to those who only completed the baseline using chi-squared tests. Appendix 1 compares those retained in the study and those who were lost to follow-up. Those who remained in the study were significantly more likely to be female (60 percent vs. 49 percent), married/cohabiting (52 percent vs. 42 percent), and urban residents (75 percent vs. 61 percent). This lower retention among unmarried men in rural areas may be due to migration and seasonal labor. There were no differences by age or wealth. HIV prevention programs in Zambia must incorporate alcohol risk reduction activities. Further, lessons learned from income generation programs and programs addressing harmful gender norms should be used to strengthen other HIV prevention programs. Stata 12.1 (Stata Corporation, College Station, Texas USA) was used for data analysis. 


\section{Sample Characteristics}

Appendix 2 shows the baseline characteristics of study participants who completed both baseline and midline surveys $(\mathrm{N}=1,921)$ in each community. Overall, the median age of study participants was 26 (males) and 25 (females), and 52 percent (males) and 32 percent (females) were never married. Males in Kawama were noticeably younger (median age: 22 years) and were more likely to be never married (68 percent) than males in other communities. The majority of participants in Kawama were urban residents (over 95 percent), whereas the other communities were primarily rural-based (approximately 80-100 percent). Education and wealth varied greatly by community. Those in Kawama were more educated and were more likely to be in the higher wealth index ${ }^{2}$ than those in other communities; Chinyunyu residents were the least wealthy.

\section{Exposure to COMPACT Activities}

Participants were asked if they had participated in any of the COMPACT activities in the past 12 months. Overall, approximately 40 percent had been exposed to at least one of the intervention activities (Appendix 3). Kawama had the lowest coverage rate, with approximately 30 percent having been exposed to COMPACT activities. Specifically, approximately 10-15 percent reported having participated in each of the following COMPACT activities: the income generation program, Safe Love Clubs, Gender Action Groups, PLHIV support groups, and Safe Spaces for Girls ${ }^{3}$. About a quarter reported having been exposed to alcohol abuse prevention activities (males: 29 percent; females: 25 percent). Those in Kawama reported very little exposure to the income generation program, Safe Love Clubs, Gender Action Groups, and Safe Spaces for Girls. Appendix 4 shows the comparison of unexposed and exposed persons. Exposed persons were more educated, slightly older, and more likely to be rural residents. Exposure did not vary significantly by sex, marital status, wealth, or HIV knowledge at baseline. The main reasons for participation for both males and females in all communities were to learn about HIV/AIDS (approximately 75 percent) and to share experiences with others (approximately 15 percent) (Appendix 3).

\section{Changes in Key Outcomes}

Appendix 5 provides details of indicators of knowledge, attitudes, and practices at baseline and midline in each community by exposure to COMPACT.

Significant positive changes in some outcomes were associated with exposure to COMPACT activities. These outcomes included support of equitable gender norms, sex with non-regular partners, and alcohol abuse. The following highlights these changes:

\footnotetext{
${ }^{2}$ The wealth index uses Zambia Demographic and Health Survey's measures of a household's long-term standard of living, which is based on the household's ownership of consumer goods, dwelling characteristics, and other characteristics related to a household's socio-economic status.

${ }^{3}$ The Safe Spaces program is targeted for girls between the ages of 12 and 19 years. The exposure is assessed among girls 15 to 19 years.
} 


\section{Equitable gender norms ${ }^{4}$ and rape myths ${ }^{5}$}

Overall, there was a significant increase from baseline to midline in the proportion of all females supporting equitable gender norms (from approximately 65 percent to 80 percent). Of note, however, in Chinyunyu and Chongwe, women who were exposed to COMPACT were significantly more likely to change their attitudes to support equitable norms from baseline to midline compared to those who were not exposed (Figure 1). In most communities, there was no statistically significant increase in the proportion of males supporting equitable gender norms.

Rape myths were supported by approximately half of both males and females at baseline. Overall, support for rape myths decreased from baseline to midline equally in both exposed and unexposed males and females (by about 20 to 30 percent) (Figure 2). Exposed females in Chongwe and Kaniki were significantly more likely to change their views (i.e., disavow these myths) compared to unexposed females (Appendix 3).

Figure 1. Females supporting equitable gender norms by exposure to COMPACT at baseline and midline

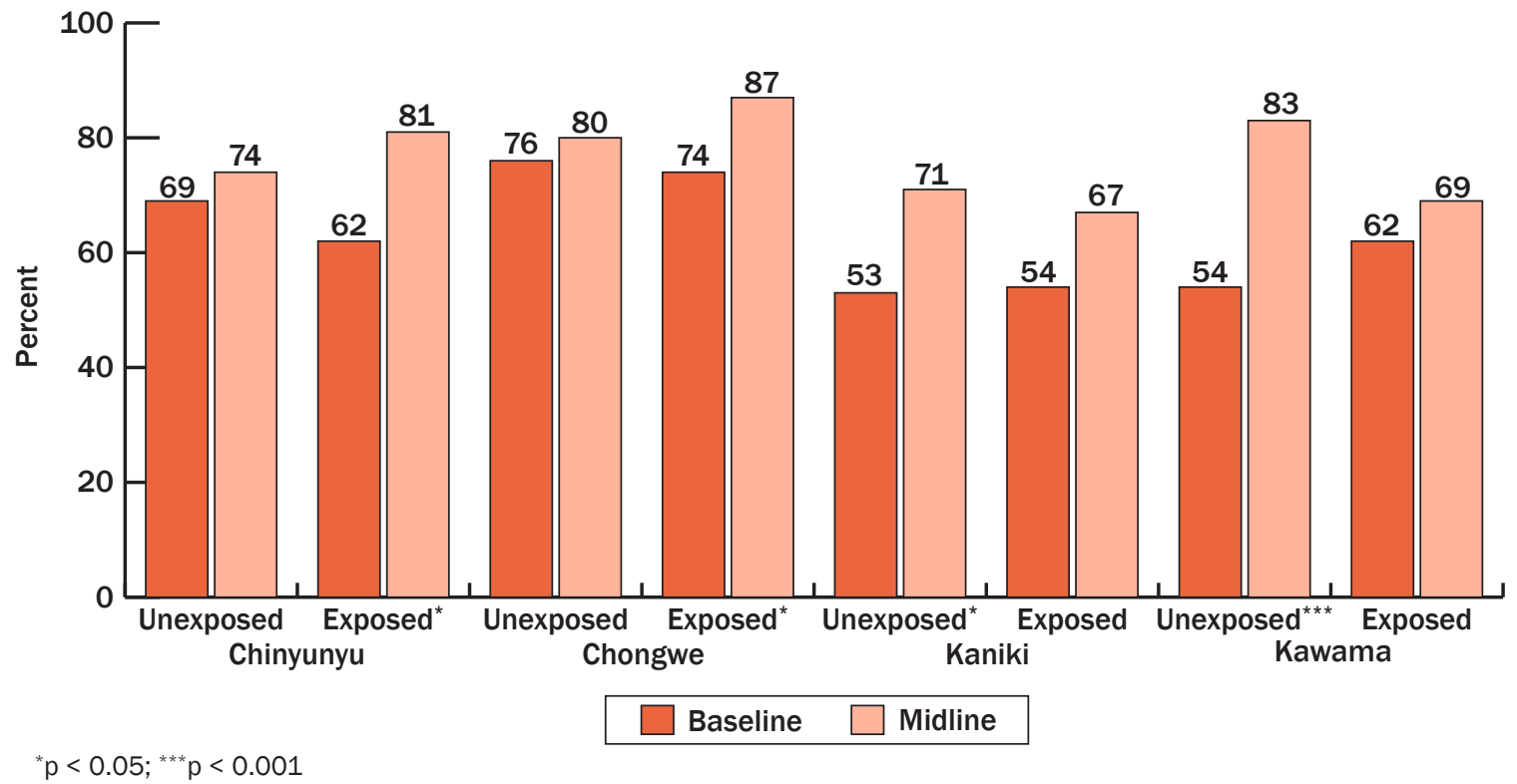

${ }^{4}$ Attitudes toward gender relations were measured using 15 items adapted from the Gender Equitable Men scale (Pulerwitz and Barker 2008). A typical item in the scale is "A man should have the final word about decisions in his home."

${ }^{5}$ Rape Myths: A participant is considered to support rape myths if he/she agreed to any two of four rape myths items (i.e., "If a woman doesn't physically fight back, you can't really say it was rape" or “In some cases women actually want it to happen"). 
Figure 2. Males and females supporting rape myths by exposure to COMPACT at baseline and midline

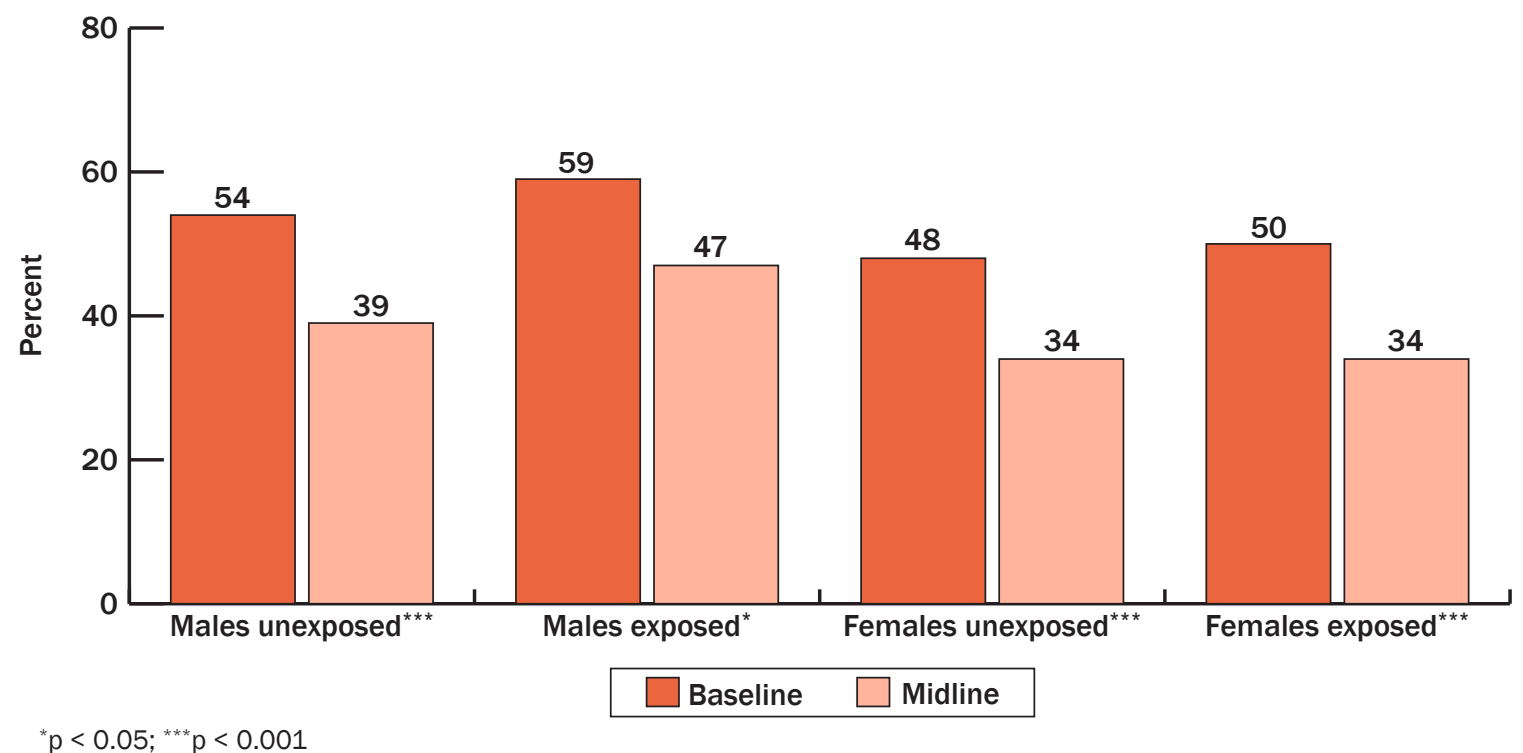

\section{Risky sexual behaviors}

Overall, among males, the proportion reporting sex with a non-regular partner ${ }^{6}$ decreased significantly from baseline to midline only among those exposed (from 37 percent to 18 percent; $p$ $<0.05$ ) while it remained steady at 31-34 percent among unexposed males (Figure 3). Only a small proportion of females reported sex with a non-regular partner (approximately 15 percent at both baseline and midline) in all communities. At midline in all communities combined, approximately 53-61 percent reported condom use at last sex with their non-regular partner; there was no significant difference by exposure status. ${ }^{7}$

Overall, multiple sex partnerships were not common among females. However, despite the small proportion of females reporting more than one partner in the last 12 months, it decreased significantly from 7 percent at baseline to 2-4 percent (regardless of exposure). Among males overall, decreases were observed in both the exposed group (from 16 percent to 11 percent; $p$ $=0.07$ ) and the unexposed groups (15 percent to 10 percent; $p<0.05$ ) (Figure 4). At midline, approximately 55-61 percent reported condom use at last sex among those who had multiple sex partners in the last 12 months; there was no significant difference in condom use by exposure status. $^{7}$ There were, however, significant increases from baseline to midline in the proportion indicating that they can get condoms if they wanted to in both males (from 60 percent to 85 percent) and females (50 percent to 65 percent).

\footnotetext{
${ }^{6} \mathrm{~A}$ non-regular partner was defined as a partner who is not a spouse or live-in partner. It includes boyfriend/girlfriend, a casual acquaintance, or a sex worker.

${ }^{7}$ There are no estimates for condom use at last sex at baseline due to a large number of missing data in this section.
} 
Figure 3. Percent of males and females having at least one non-regular partner in the last 12 months by exposure to COMPACT at baseline and midline (All communities)

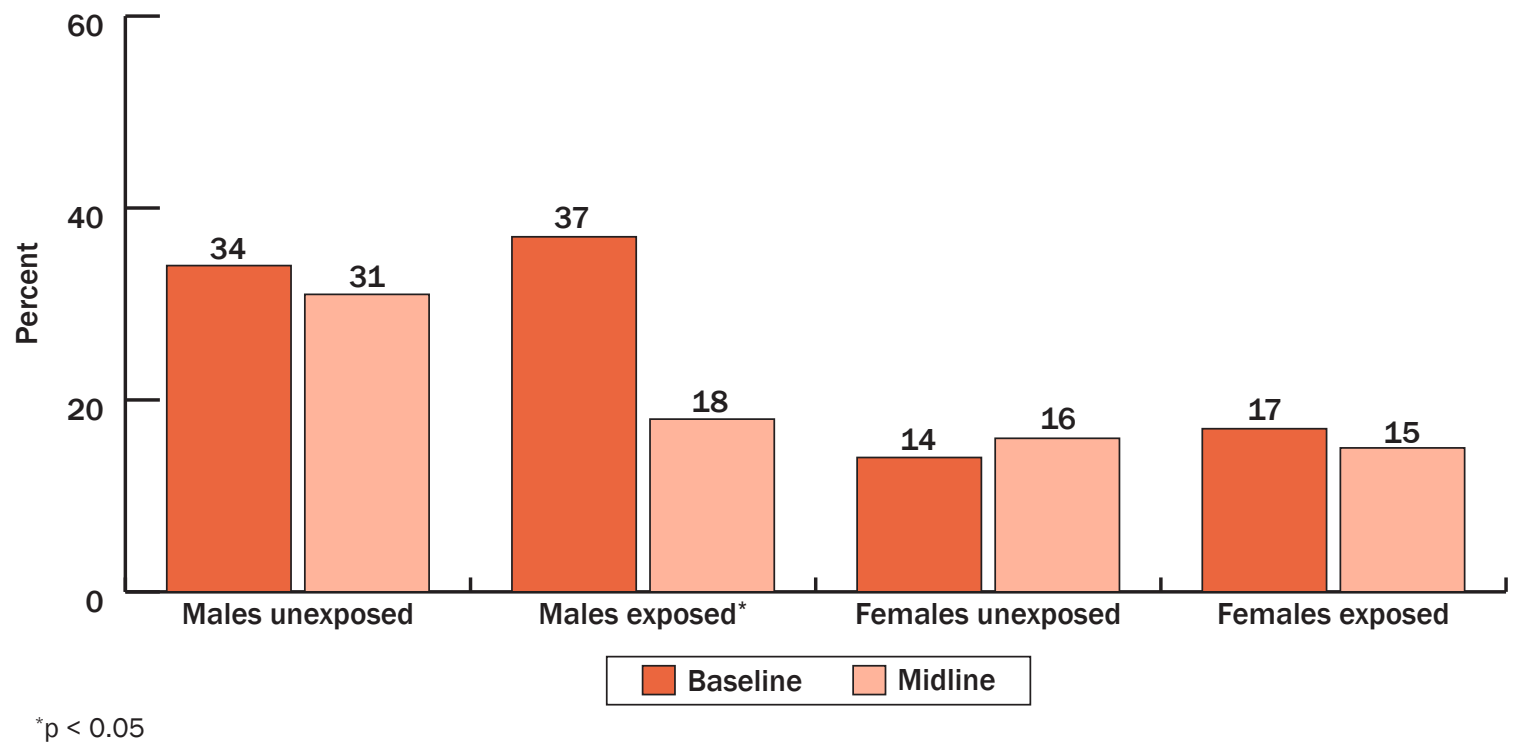

Figure 4. Percent of males and females having multiple sex partners in the last 12 months by exposure to COMPACT at baseline and midline (All communities)

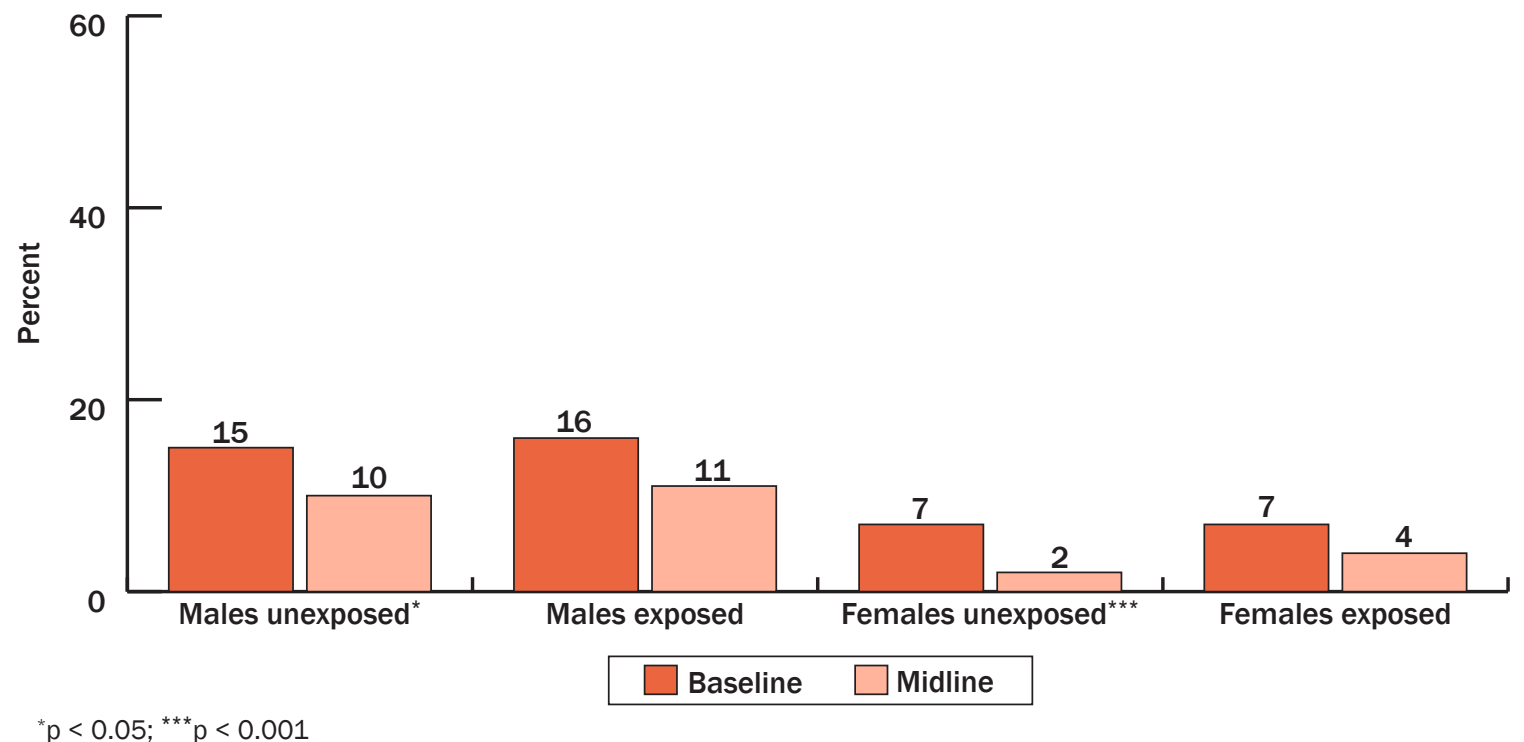

\section{Alcohol abuse}

Clinical alcohol problems ${ }^{8}$ were more common among males (approximately 20-30 percent) than females (less than 15 percent in all communities). Figure 5 shows the levels of alcohol problems among males. In Chinyunyu, there were significant declines in alcohol problems from baseline to

${ }^{8}$ Alcohol Problem: Alcohol abuse was assessed using the CAGE 4-item questionnaire Ewing, J. A. (1984). "Detecting alcoholism. The CAGE questionnaire," JAMA 252(14): 1905-1907. The items include feeling the need to cut down on drinking, being annoyed by people criticizing drinking, feeling guilty about drinking, and needing an eye-opener first thing in the morning. An affirmative response on two or more of the items was considered to be a clinically significant alcohol problem. 
midline and the decline was greater in the exposed group (by 56 percent) compared to the unexposed group (by 41 percent). In other communities, the prevalence of alcohol problems for the most part remained unchanged around 20-40 percent.

Figure 5. Clinical alcohol problems among males by exposure to COMPACT at baseline and midline

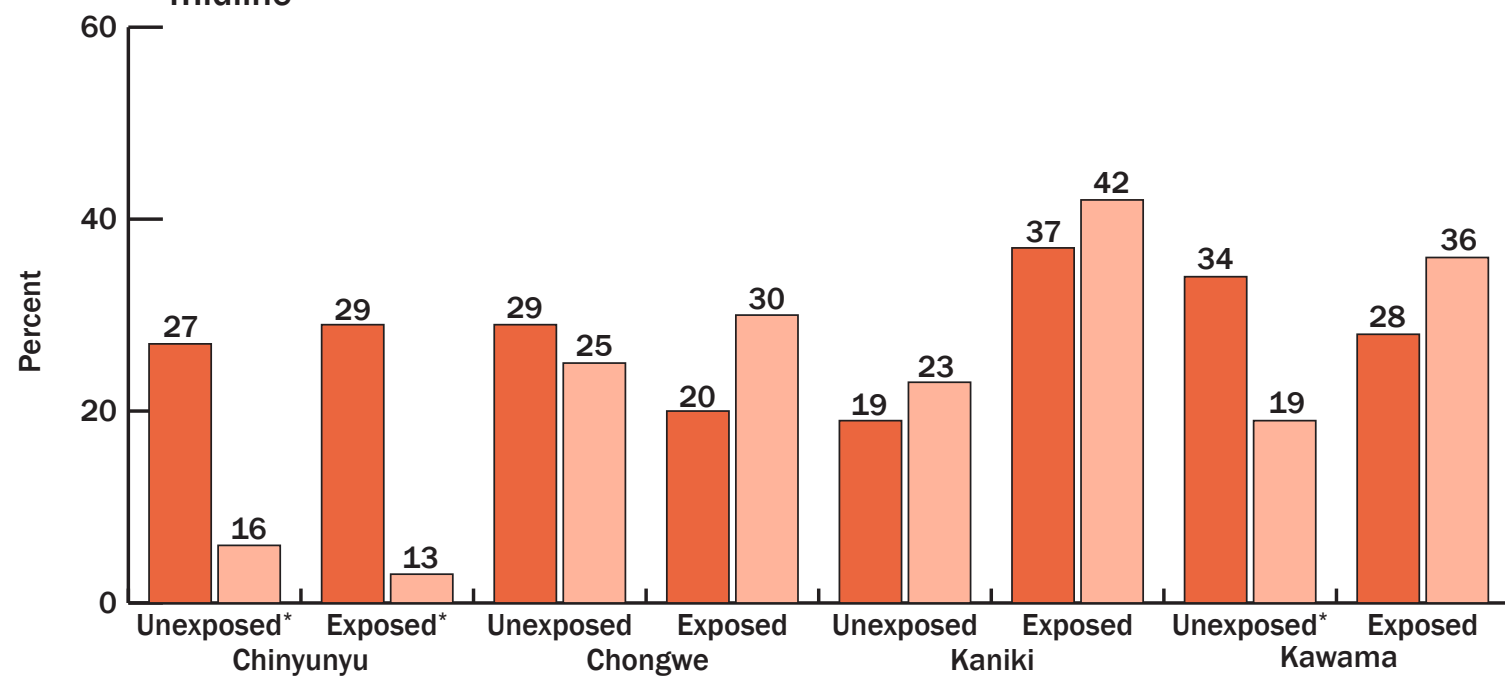

${ }^{*} p<0.05$

For a few outcomes, there were significant improvements from baseline to midline but the improvements did not vary by exposure to COMPACT. These outcomes include HIV knowledge and HIV testing history.

\section{HIV knowledge}

Comprehensive HIV knowledge ${ }^{9}$ varied greatly at baseline, from as low as approximately 30 percent in Chinyunyu to 50-60 percent in other communities. The increases from baseline to midline also varied across community. Chinyunyu demonstrated the greatest increase: the level of comprehensive HIV knowledge doubled in males and increased by one-third in females. There was no difference by exposure status.

\section{Ever HIV testing and receiving results}

HIV testing increased significantly from baseline to midline in all communities in both males and females regardless of exposure to COMPACT. In total among males, testing increased from 41 percent to 69 percent among unexposed (a 71 percent increase) and from 50 percent to 78 percent among exposed (a 57 percent increase). Among females combined, HIV testing rates were already

\footnotetext{
${ }^{9}$ Comprehensive HIV and AIDS knowledge was defined as: i) knowing that both condom use and limiting sex partners to one uninfected partner are HIV prevention methods; ii) being aware that a healthy-looking person can have HIV; and iii) rejecting the common misconceptions that HIV and AIDS can be transmitted through supernatural means or mosquito bites.
} 
fairly high at baseline (ranging from 63 percent to 82 percent) and significantly increased to over 80 percent in all communities regardless of exposure. However, Chinyunyu demonstrated the greatest increase in testing in both males and females and exposed and unexposed. The percentage tested at midline more than doubled from baseline in males (Unexposed: 31 percent to 67 percent; Exposed: 40 percent to 80 percent) and a 40 percent increase from baseline in females (Unexposed: 62 percent to 88 percent; Exposed: 64 percent to 88 percent). Other communities demonstrated an average increase of 50 percent in males and 15 percent in females.

For a number of outcomes, there were no changes or changes in the opposite direction than expected. These include HIV-related stigma and sexual and physical violence.

\section{Acceptance of people living with HIV (PLHIV)}

In all communities except Chongwe, attitudes toward PLHIV did not change from baseline to midline. The percentage with accepting attitudes toward PLHIV remained steady at 15-35 percent. However, in Chongwe, levels of acceptance actually significantly decreased from 40-60 percent at baseline to approximately 30 percent at midline, regardless of exposure.

\section{Physical and sexual violence}

In all communities, females reported experiencing physical or sexual violence in significantly greater proportions at midline compared to baseline. Report of abuse increased from 5 percent to 13 percent in the unexposed group (a 1.7 times increase) and from 4 percent to 16 percent in the exposed group (a 2.5 times increase) (Figure 6). In all communities except Chinyunyu, the increase in reporting violence was much greater in the exposed group compared to the unexposed group.

\section{Figure 6. Experience of physical or sexual violence in last 12 months among females}

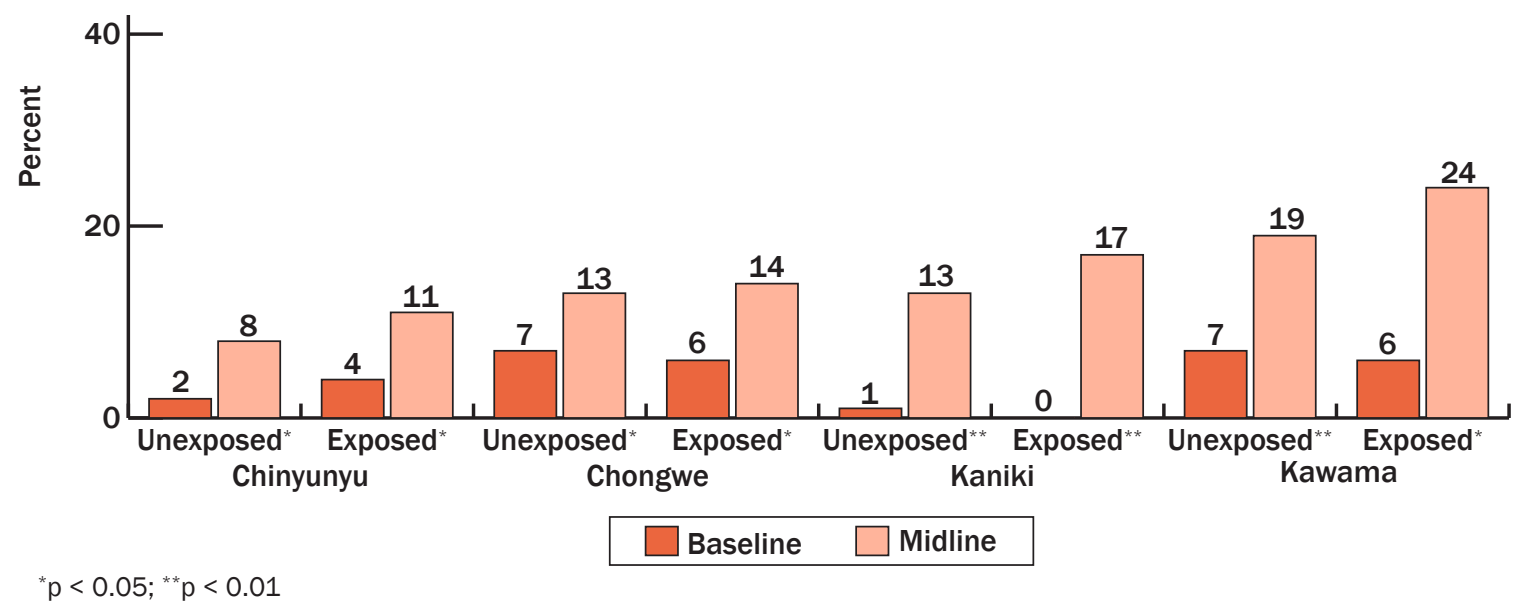




\section{Adolescent (15-19 years)}

The sample size is too small to examine community-specific changes for adolescents so findings are combined. Among those who were adolescents at baseline, level of sexual activity in the last 12 months remained the same from baseline to midline for both boys and girls regardless of exposure (Appendix 6). Among boys, it remained the same around 30-35 percent in both exposed and unexposed. Among girls, sexual activity remained unchanged at 40 percent among unexposed and 30 percent among exposed. The sample size was too small to examine multiple partnerships and having non-regular partners among adolescents. Girls were asked if they were aware of ways to avoid pregnancy. There were significant increases in awareness for both exposed (39 percent to 66 percent) and unexposed groups (40 percent to 83 percent), with the exposed group showing a greater increase (104 percent increase) compared to the unexposed group (70 percent increase). Contraceptive use among adolescent girls significantly increased by threefold (from approximately 10 percent to 30 percent); there was no difference by exposure. Unintended pregnancy at last birth among girls remained unchanged from baseline to midline in both exposed (around 60-65 percent) and unexposed (around 75-80 percent) groups.

\section{HIV seroincidence}

Of the 697 participants who have both baseline and midline behavioral interviews, 456 (65 percent) had both baseline and midline HIV test results. A total of 241 (35 percent) participants refused to provide blood for HIV testing, primarily due to lack of incentives provided for the blood draw especially since this was the second time giving a blood sample. Table 1 shows that those who did not have both baseline and midline HIV test results were not significantly different from those who had both results with regard to demographic characteristics, HIV testing history, and risky sexual behaviors. 
Table 1. Comparison of those those who did not have both baseline and midline HIV test results $(n=241)$ with those who did $(n=456)$ in Kaniki and Kawama

\begin{tabular}{|c|c|c|c|}
\hline & $\begin{array}{c}\text { Those with } \\
\text { incomplete HIV data } \\
\%(n) \\
(n=241)\end{array}$ & $\begin{array}{c}\text { Those with } \\
\text { complete HIV data } \\
\%(n) \\
(n=456)\end{array}$ & p-value \\
\hline \multicolumn{4}{|l|}{ Sex } \\
\hline Male & $34.0(82)$ & $38.2(174)$ & 0.282 \\
\hline Female & $66.0(159)$ & $61.8(282)$ & \\
\hline \multicolumn{4}{|l|}{ Age groups } \\
\hline $15-24$ & $50.2(121)$ & $44.5(203)$ & 0.152 \\
\hline $25+$ & $49.8(120)$ & $55.5(253)$ & \\
\hline \multicolumn{4}{|l|}{ Community } \\
\hline Kaniki & $43.2(104)$ & $48.5(221)$ & 0.181 \\
\hline Kawama & $56.9(137)$ & $51.5(235)$ & \\
\hline \multicolumn{4}{|l|}{ Marital status } \\
\hline Never married & $39.7(93)$ & $35.7(160)$ & 0.184 \\
\hline Married/Living together & $49.2(115)$ & $56.0(251)$ & \\
\hline Divorced/Separated/Widowed & $11.11(26)$ & $8.3(37)$ & \\
\hline \multicolumn{4}{|c|}{ Ever tested and received results (midline) } \\
\hline No & $20.0(48)$ & $21.2(94)$ & 0.708 \\
\hline Yes & $80.0(192)$ & $78.8(349)$ & \\
\hline \multicolumn{4}{|c|}{ Multiple sex partners in last 12 months (midline) } \\
\hline No & $95.8(230)$ & $97.1(430)$ & 0.394 \\
\hline Yes & $4.2(10)$ & $2.9(13)$ & \\
\hline \multicolumn{4}{|c|}{$\begin{array}{l}\text { Had sex with non-regular partner in last } 12 \\
\text { months (midline) }\end{array}$} \\
\hline No & $81.7(196)$ & $84.9(376)$ & 0.278 \\
\hline Yes & $18.3(44)$ & $15.1(67)$ & \\
\hline
\end{tabular}

Of the 456 participants, 75 (16 percent) were seropositive at baseline. Thus, we examined HIV seroincidence among the remaining 381 (194 in Kaniki and 187 in Kawama) participants who were HIV seronegative at baseline. The demographic characteristics of the 381 HIV negative participants are described in Table 2. 
Table 2. Demographic characteristics of those who were HIV negative at baseline in Kaniki $(n=194)$ and Kawama $(n=187)$

\begin{tabular}{|lc|}
\hline & $\%(n)$ \\
Sex & $n=381$ \\
$\quad$ Male & \\
Female & $40.7(155)$ \\
Age & $59.3(226)$ \\
$15-24$ & \\
$25-34$ & $49.3(188)$ \\
$35+$ & $24.9(95)$ \\
Marital status & $25.7(98)$ \\
Never married & \\
Married/Cohabiting & $40.8(152)$ \\
Divorced/Separated/Widowed & $53.6(200)$ \\
\hline
\end{tabular}

A total of 6 (Kaniki) and 5 (Kawama) new HIV infections occurred over a cumulative 234.6 and 217.5 person years of follow-up, respectively. (Table 3) This results in a seroincidence rate of 2.6 new infections per 100 person-years (95\% Cl: 1.1-5.7) in Kaniki and 2.3 new infections per 100 person-years (95\% $\mathrm{Cl}: 1.0-5.5)$ in Kawama.

Table 3. HIV seroincidence in Kaniki and Kawama ${ }^{a}$

\begin{tabular}{|lcc|}
\hline Number of seroconversions & $\begin{array}{c}\text { Kaniki } \\
(\mathrm{n}=194)\end{array}$ & $\begin{array}{c}\text { Kawama } \\
(\mathrm{n}=187)\end{array}$ \\
Total person years of follow-up & 6 & 5 \\
Incidence /100 person years $(95 \% \mathrm{Cl})$ & 234.6 & 217.5 \\
\hline
\end{tabular}

${ }^{a}$ This is restricted to participants who were seronegative at baseline and have both baseline and midline HIV test results.

We examined incidence by select characteristics for Kaniki and Kawama together given the small number of seroconversions. (Table 4) While the number of new HIV infections is too small to result in significant associations for most variables or to conduct any multivariate analysis, some trends could be observed. For example, although not significant, females were almost twice as likely to seroconvert than males, those 35 years or older were 3.4 times more likely to seroconvert compared to the younger group (15-24 years), and divorced/widowed persons were 2.6 times more likely to seroconvert compared to those never married.

With regard to sexual behaviors, we found that those with less risky sexual behaviors were actually more likely to seroconvert. Specifically, those who did not have multiple sex partners in the last 12 months had an incidence rate of 2.3/100 PY, and those who did not have non-regular partners in the last 12 months had an incidence of 1.7/100 PY. However, those who had sex with non-regular partners or had multiple sex partners in the last 12 months had zero seroconversions. 
Having a clinical alcohol abuse problem was significantly associated with HIV seroconversion. Those who had an alcohol abuse problem had a seroincidence rate of $6.7 / 100$ PY while those who did not have a problem had a rate of 1.6/100 PY $(p<0.01)$.

We also examined seroconversion by participation in the different HIV prevention activities under COMPACT. Participation in income generation programs and Gender Action Groups appear to have a protective association. Higher HIV incidence was found among those who did not participate in income generation programs (2.6/100 PY) or Gender Action Groups (2.7/100 PY). There were zero seroconversions among those who participated in these programs. There was no difference in seroincidence by participation in the Safe Loveor Space Spaces programs. The data suggests a possible association $(p=0.081$ ) with alcohol education programs in the opposite direction as expected as incident cases were higher among those who participated in alcohol education (4.3/100 PY) than those who did not (1.8/100 PY). 
Table 4. HIV incidence by select characteristics among the HIV negative cohort in Kaniki and Kawama $(n=381)^{a}$

\begin{tabular}{|c|c|c|c|}
\hline & $\begin{array}{c}\text { Incidence per } 100 \\
\text { person-years }(95 \% \mathrm{Cl})\end{array}$ & $\begin{array}{l}\text { Hazard } \\
\text { ratio }\end{array}$ & p-value \\
\hline \multicolumn{4}{|l|}{ Sex } \\
\hline Male & $1.6(0.5-5.1)$ & 1.0 & \\
\hline Female & $3.0(1.5-6.0)$ & 1.8 & 0.384 \\
\hline \multicolumn{4}{|l|}{ Age } \\
\hline $15-24$ & $1.3(0.4-4.1)$ & 1.0 & \\
\hline $25-34$ & $2.7(0.9-8.2)$ & 2.0 & 0.394 \\
\hline $35+$ & $4.4(1.8-10.6)$ & 3.4 & 0.097 \\
\hline \multicolumn{4}{|l|}{ Marital status } \\
\hline Never married & $1.7(0.5-5.1)$ & 1.0 & \\
\hline Married/Cohabiting & $2.5(1.1-5.6)$ & 1.5 & 0.579 \\
\hline Divorced/Separated/Widowed & $4.2(0.6-30.1)$ & 2.6 & 0.414 \\
\hline \multicolumn{4}{|c|}{ Multiple sex partners in last 12 months (midline) } \\
\hline No & $2.3(1.3-4.3)$ & - & - \\
\hline Yes & 0.0 & & \\
\hline \multicolumn{4}{|c|}{ Had sex with non-regular partner in last 12 months (midline) } \\
\hline No & $2.7(1.4-5.0)$ & - & - \\
\hline Yes & 0.0 & & \\
\hline \multicolumn{4}{|c|}{ Has clinical alcohol abuse problem (midline) } \\
\hline No & $1.6(0.7-3.5)$ & 1.0 & \\
\hline Yes & $6.7(2.8-16.0)$ & 5.7 & $<0.010$ \\
\hline \multicolumn{4}{|l|}{ Participated in Safe Love program } \\
\hline No & $2.4(1.3-4.4)$ & 1.0 & \\
\hline Yes & $3.4(0.5-23.8)$ & 1.7 & 0.611 \\
\hline \multicolumn{4}{|c|}{ Participated in Safe Spaces program } \\
\hline No & $3.0(1.4-6.3)$ & 1.0 & \\
\hline Yes & $2.8(0.4-19.7)$ & 1.0 & 0.980 \\
\hline \multicolumn{4}{|c|}{ Participated in Alcohol Education program } \\
\hline No & $1.8(0.8-4.0)$ & 1.0 & \\
\hline Yes & $4.3(1.8-10.2)$ & 2.8 & 0.081 \\
\hline \multicolumn{4}{|c|}{ Participated in income generation program } \\
\hline No & $2.6(1.4-4.7)$ & - & - \\
\hline Yes & 0.0 & & \\
\hline \multicolumn{4}{|c|}{ Participated in Gender Action Group program } \\
\hline No & $2.7(1.5-4.9)$ & & \\
\hline Yes & 0.0 & - & - \\
\hline
\end{tabular}

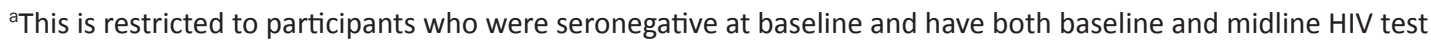
results. 


\section{CONCLUSION AND NEXT STEPS}

These findings suggest that COMPACT has had some impact in some areas of HIV prevention and related areas. Most notably, there were improvements in some indicators such as decreases in males having non-regular sex partners, increases in females supporting equitable gender norms, and decreases in reported alcohol problems. These improvements were associated with exposure to COMPACT. Further, participation in income generation activities and Gender Action Groups were found to be protective against HIV seroconversion.

Additionally, Chinyuyu stands out as the community where the impact of the COMPACT intervention has been the greatest. It is important to point out that Chinyunyu is the only one of the four COMPACT communities where COMPACT is the first systematic and large-scale HIV prevention program to be implemented and there were none or minimal other HIV prevention programs being implemented during the same time as COMPACT. The other three communities have more organizations implementing various HIV prevention interventions. Thus the measurements of exposure to COMPACT in those three communities were more likely to have been confounded by impacts from other HIV projects and even those who were not exposed to COMPACT may have received HIV prevention messages and services through other programs. That being said, many of the outcome indicators did improve from baseline to midline regardless of exposure in all communities (HIV knowledge, HIV testing, belief in rape myths, multiple sex partnerships). People not directly exposed to COMPACT interventions were also living in the same communities as people who were, and thus possibly experienced indirect exposure through discussions with exposed persons. Therefore, the COMPACT intervention may have contributed to improvements in these communities. It should be noted that Chinyunyu still demonstrated the greatest increases in some of these indicators compared to other communities since baseline rates were lower than other communities. The dramatic increase is likely a result of the community being exposed to HIV prevention interventions systematically for the first time.

It is not surprising that HIV knowledge and testing increases were widespread regardless of specific exposure to COMPACT since Zambia has been promoting HIV testing on a large scale. While testing rates have increased, this study shows that HIV testing in men remains lower than that of women. COMPACT should consider conducting more male-centered/sensitive HIV counseling and testing campaigns.

This study found levels of acceptance of PLHIV unchanged or even decreased in communities. COMPACT will need to strengthen its efforts to reduce stigma toward PLHIV.

It is encouraging that there were decreases in multiple partnerships (in both males and females) as well as males having non-regular regular partners (only among exposed). Safe Love Clubs may be having an impact on sexual behaviors and should strengthen its efforts to reach more men. Although there were reductions in riskier partnerships and there were increases in the proportion of males and females indicating they could get condoms if they wanted to, condom use among those who had multiple partners or non-regular partners at midline remained moderate at 50-60 percent. COMPACT should make a greater effort to increase condom use among those engaging in higher risk sex.

While it is disconcerting that reports of physical and sexual violence increased in both exposed and unexposed groups in all communities, there were decreases in support of rape myths across all communities. Thus, the greater reports of violence may be due to greater awareness that 
physical and sexual violence are not acceptable regardless of the circumstances. There may have also been increased comfort in reporting violence to interviewers at midline. These issues make it challenging to measure changes in experience of abuse because of the change in perception of what participants consider violence and their level of comfort in reporting violence between the two time points. With more women recognizing their experiences of gender-based violence, there also needs to be supportive systems (health, legal, and psychosocial services) in place for survivors of violence.

This study also showed that adolescents who were not sexually active at baseline were choosing to delay initiating sexual activity. Results also showed that knowledge of pregnancy avoidance strategies increased more among those exposed to COMPACT interventions. Additionally, there was an increase in contraceptive use among sexually active girls, although it remains relatively low. These finding suggest that COMPACT should continue its activities targeting adolescent girls and strengthen its efforts to ensure that young girls are able to access family planning.

We found high HIV seroincidence in the two communities of Kaniki and Kawama. These two communities are located in Copperbelt province, which has typically had higher HIV prevalence compared to many other parts of Zambia (Zambia Central Statistical Office 2007). Consistent with these findings, the current analysis also indicates that there is a high level of HIV sero-incidence in these two communities in Zambia. This is higher than the estimated national HIV incidence rate of 1.12/100 PY (for 2002-2007) (Hallett et al. 2010). The national HIV incidence estimate by Hallett et al. is based on modelling using two cross-sectional national seroprevalence surveys, where our seroincidence rate is from two specific communities based on a probability-based sample. Of note, more localized seroincidence rates have been reported as high as 2.6/100 PY among a prevention trial cohort of Lusaka women, and 4.7 percent among a clinical trial cohort of Lusaka women (Celum et al. 2008, Kapina et al. 2009). The seroincidence rate among our study's female cohort (3.0/100 PY) is in line with these two studies.

The small sample size of those who seroconverted limits our ability to draw conclusions about factors associated with HIV seroconversion. However, we found several significant associations. First, HIV seroconversion was negatively associated with higher risk behaviors (multiple sex and non-regular partnerships in the last 12 months). This may be because those who engage in higher risk sex use condoms more often than those who have only one partner or have only a regular partner. In fact, in further examining our data, we found that those who engaged in higher risk sex were significantly more likely to use condoms compared to those who did not engage in higher risk sex.

Second, we found that HIV seroconversion was significantly more common among those who reported alcohol abuse. Systematic reviews, including many African studies, have found consistent positive association between alcohol use and sexual risk taking (Cook and Clark 2005, Fisher et al. 2007, Kalichman et al. 2007, Browne and Wechsberg 2010). A recently published study on the effect of hazardous drinking on HIV incidence in female sex workers round that hazardous drinkers were significantly more likely (10 times) to seroconvert compared to non-drinkers (Chersich et al. 2014). There is clearly a need for HIV programs to address and integrate alcohol abuse risk reduction. For example, during HIV counseling and testing, counselors could be given appropriate tools to evaluate alcohol abuse using the CAGE tool (Ewing 1984) and recommend strategies for reducing risk related to alcohol abuse. In light of the fact that we did not find a reduction in alcohol abuse in Kaniki and Kawama, COMPACT should examine ways to strengthen its alcohol risk reduction activities. 
Lastly, we found that participation in certain COMPACT programs were in fact protective against HIV seroconversion. Those who participated in the Gender Action Groups and the income generation programs were less likely to seroconvert. We examined if this was an effect of selection bias in program participation (i.e., were those who were less risky more likely to participate in these programs?). We found no selection bias in participation in any of the COMPACT activities. Thus, this indicates a likely positive shift due to HIV prevention activities, including those of the COMPACT project. Further, survey data indicated that there was an increase in support of gender equitable norms and decrease in support of rape myths from baseline to midline. This suggests that these program activities (Gender Action Groups and income generation activities) led to positive shifts in gender norms, and this also contributed to reduced HIV seroconversion. It would be worth examining if some of the components from these two programs could be incorporated into the other COMPACT programs, such as the Safe Love Clubs and Safe Spaces, which do not appear to be having an effect on HIV seroconversion.

There are limitations of the study that should be highlighted. Since there was no separate comparison community, those who were not directly exposed to the intervention may actually have been indirectly exposed through peers who were directly exposed to and participated in the COMPACT activities, thus making it difficult to examine the effect of exposure. Secondly, there was a high loss to follow-up, largely due to typical migration patterns; thus the generalizability of the findings may be somewhat compromised. The surveys were conducted during different times of the year-baseline during the hot and dry season of October to December and midline through the rainy season of November through June-and seasonal labor may have affected responses. Lastly, COMPACT is not the only HIV prevention intervention in these communities, with the exception of Chinyunyu. Therefore, it is difficult to assess true exposure to the COMPACT program. Other organizations that were not part of COMPACT may have been implementing similar HIV prevention programs. Hence, exposure to interventions in this study may reflect exposure to HIV prevention interventions besides solely COMPACT activities.

In conclusion, the study findings suggest that COMPACT is improving some HIV-related behaviors and attitudes, particularly those related to gender norms, multiple sex partnerships, and alcohol abuse. Further, in order to reduce HIV incidence and prevalence, HIV prevention programs in Zambia must incorporate alcohol risk reduction activities. Lastly, lessons learned from income generation programs and programs addressing harmful gender norms should be used to strengthen other HIV prevention programs. 


\section{REFERENCES}

Browne, F. A. and W. M. Wechsberg. 2010. "The intersecting risks of substance use and HIV risk among substance-using South African men and women," Curr Opin Psychiatry 23(3): 205-209.

Celum, C. et al. 2008. "Effect of aciclovir on HIV-1 acquisition in herpes simplex virus 2 seropositive women and men who have sex with men: a randomised, double-blind, placebo-controlled trial," Lancet 371(9630): 2109-2119.

Central Statistical Office, Ministry of Health, Zambia. 2007. "Zambia Demographic and Health Survey 2007". Calverton, Maryland, USA: Tropical Diseases Research Centre, University of Zambia, and Macro International Inc.

Chersich, M. F. et al. 2014. "Effects of hazardous and harmful alcohol use on HIV incidence and sexual behaviour: a cohort study of Kenyan female sex workers," Global Health 10: 22.

Cook, R. L. and D. B. Clark. 2005. "Is there an association between alcohol consumption and sexually transmitted diseases? A systematic review," Sexually Transmitted Diseases 32(3): 156-164.

Ewing, J. A. 1984. "Detecting alcoholism. The CAGE questionnaire," Journal of American Medical Association 252(14): 1905-1907.

Fisher, J. C., H. Bang and S. H. Kapiga. 2007. "The association between HIV infection and alcohol use: a systematic review and meta-analysis of African studies," Sexually Transmitted Diseases 34(11): 856-863.

Hallett, T. B. et al. 2010. "Estimates of HIV incidence from household-based prevalence surveys," AIDS 24(1): 147-152.

Kalichman, S. C. et al. 2007. "Alcohol use and sexual risks for HIV/AIDS in sub-Saharan Africa: systematic review of empirical findings," Prevention Science 8(2): 141-151.

Kapina, M. et al. 2009. "HIV incidence rates and risk factors for urban women in Zambia: preparing for a microbicide clinical trial," Sexually Transmitted Diseases 36(3): 129-133.

Pulerwitz, J. and G. Barker. 2008. "Measuring attitudes toward gender norms among young men in Brazil: Development and psychometric evaluation of the GEM scale," Men \& Maculinities 10: 322-338.

Zambia National HIV/AIDS/STI/TB Council, Ministry of Health, Zambia. 2009. "Zambia: HIV Prevention Response and Modes of Transmission Analysis." Lusaka: UNAIDS, World Bank Global HIV/AIDS Program.

Zambia Central Statistical Office, Ministry of Health; Tropical Diseases Research Centre, University of Zambia; and Macro International Inc. 2007. Zambia Demographic and Health Survey 2007. Calverton, Maryland, USA, Central Statistical Office and Macro International Inc. 


\section{APPENDICES}

Appendix 1. Comparison of those who had both baseline and midline behavioral data and those who do not have midline behavioral data

\begin{tabular}{|c|c|c|c|}
\hline Background characteristics & $\begin{array}{l}\text { Total participants who } \\
\text { have both baseline and } \\
\text { midline behavioral data } \\
\qquad(\mathrm{N}=1,921)\end{array}$ & $\begin{array}{l}\text { Participants who } \\
\text { do not have midline } \\
\text { behavioral data } \\
(\mathrm{N}=1,152)\end{array}$ & p-value \\
\hline Sex & & & $<0.001$ \\
\hline Male & $40.0(770)$ & $50.9(586)$ & \\
\hline Female & $60.0(1,151)$ & $49.1(566)$ & \\
\hline Median age (IQR) & $26(19-36)$ & $26(19-34)$ & \\
\hline Age groups & & & 0.594 \\
\hline $15-24$ & $46.8(898)$ & 47.7 (549) & \\
\hline $25+$ & $53.3(1.023)$ & $52.3(601)$ & \\
\hline Community & & & $<0.001$ \\
\hline Chinyunyu & $30.2(580)$ & $12.9(148)$ & \\
\hline Chongwe & $33.5(644)$ & $14.2(164)$ & \\
\hline Kaniki & $16.9(325)$ & $40.5(466)$ & \\
\hline Kawama & $19.4(372)$ & $32.5(374)$ & \\
\hline Marital status & & & $<0.001$ \\
\hline Never married & $40.0(756)$ & $48.0(546)$ & \\
\hline Married/Living together & $52.2(988)$ & $42.4(482)$ & \\
\hline Divorced/Separated/Widowed & $7.8(148)$ & $9.6(108)$ & \\
\hline Education completed & & & 0.004 \\
\hline No education & $5.4(102)$ & $5.9(68)$ & \\
\hline Primary & $37.1(707)$ & $31.1(356)$ & \\
\hline Secondary & $52.8(1,007)$ & $56.6(649)$ & \\
\hline More than secondary & $4.8(91)$ & $6.4(73)$ & \\
\hline Wealth index & & & 0.831 \\
\hline Lower & $40.2(771)$ & $39.4(454)$ & \\
\hline Middle & $19.9(382)$ & $19.5(225)$ & \\
\hline Higher & $40.0(767)$ & $41.1(473)$ & \\
\hline Residence & & & $<0.001$ \\
\hline Urban & $25.3(485)$ & $38.9(448)$ & \\
\hline Rural & $74.7(1,433)$ & $61.1(703)$ & \\
\hline
\end{tabular}

aMay not add to total due to missing data. 
Appendix 2. Baseline socio-demographic characteristics of participants who have both baseline and midline behavioral data

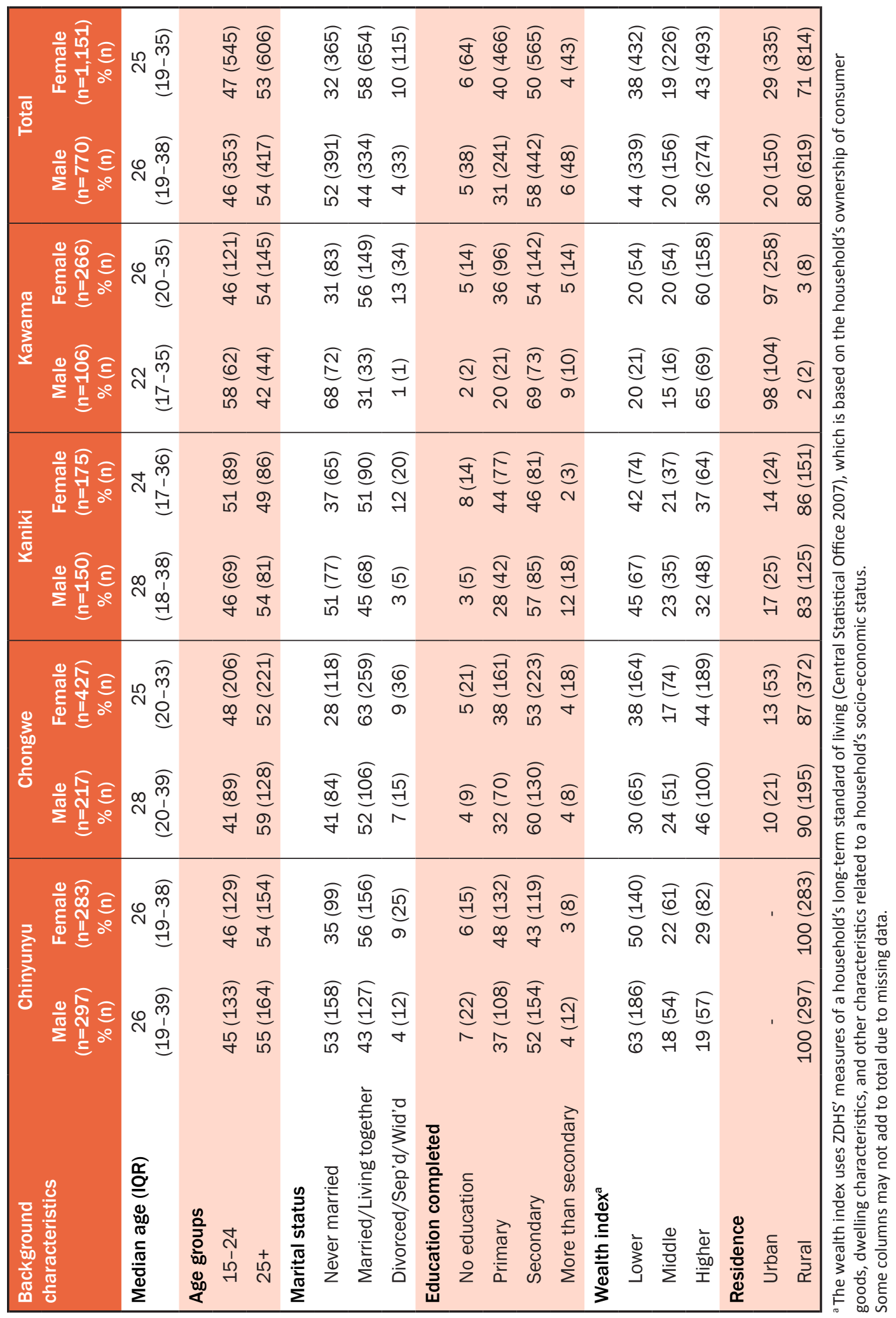



and females at midline

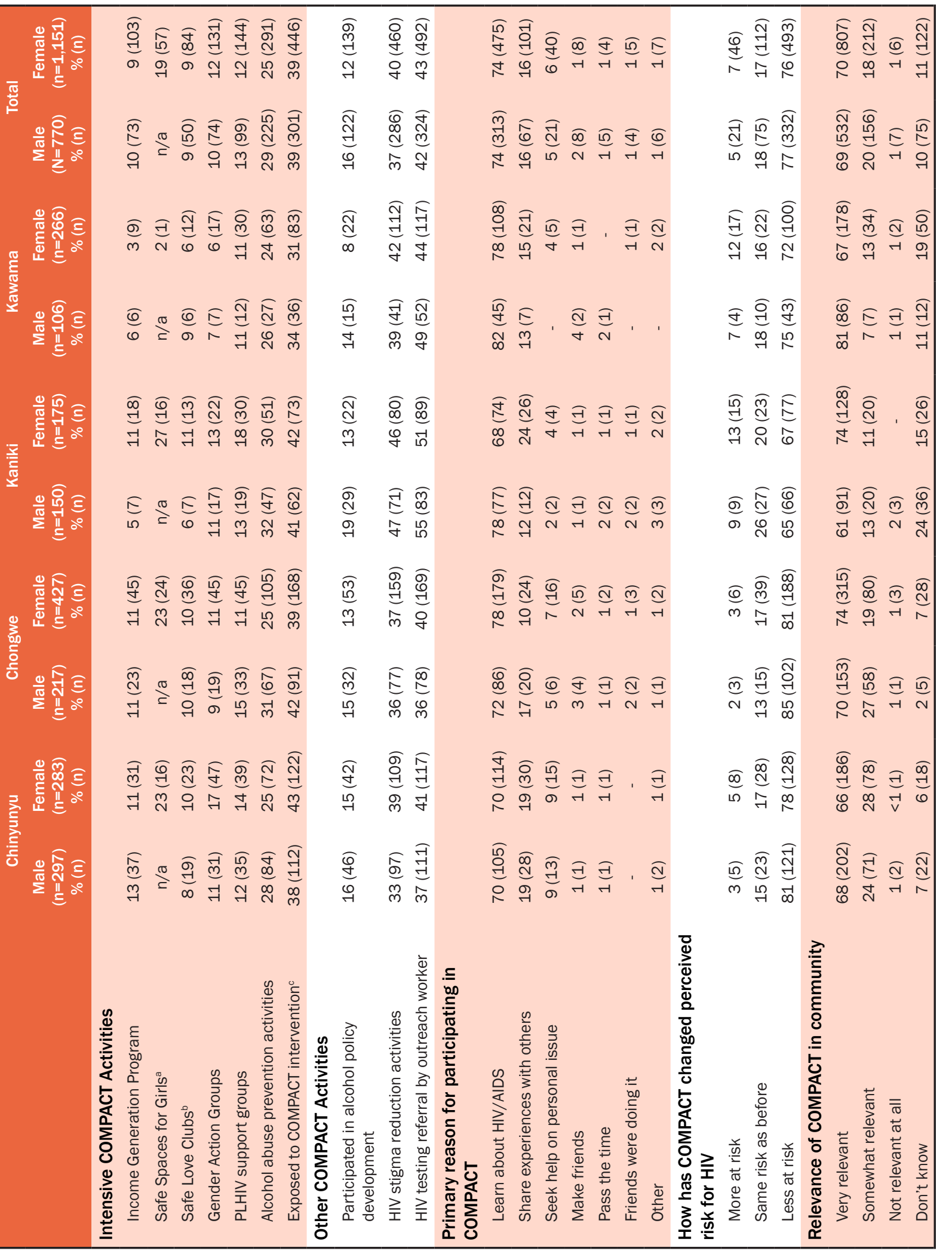


Appendix 4. Comparison of baseline characteristics for those who were exposed and unexposed to COMPACT

\begin{tabular}{|c|c|c|c|}
\hline Background characteristics & $\begin{array}{l}\text { Unexposed to } \\
\text { COMPACT } \\
(\mathrm{N}=1,166)\end{array}$ & $\begin{array}{l}\text { Exposed to } \\
\text { COMPACT } \\
(\mathrm{N}=755)\end{array}$ & p-value \\
\hline \multicolumn{4}{|l|}{ Sex } \\
\hline Male & $40(465)$ & 40 (305) & 0.821 \\
\hline Female & $60(701)$ & $60(450)$ & \\
\hline Median age (IQR) & $25(19-35)$ & $27(19-39)$ & \\
\hline \multicolumn{4}{|l|}{ Age groups } \\
\hline $15-24$ & 49 (566) & 44 (332) & 0.050 \\
\hline $25+$ & $51(600)$ & $56(423)$ & \\
\hline \multicolumn{4}{|l|}{ Marital status } \\
\hline Never married & 41 (471) & $38(285)$ & $<0.271$ \\
\hline Married/Living together & $52(596)$ & $53(392)$ & \\
\hline Divorced/Sep'd/Wid'd & $7(82)$ & $9(66)$ & \\
\hline \multicolumn{4}{|l|}{ Education completed } \\
\hline No education & $5(63)$ & $5(39)$ & 0.011 \\
\hline Primary & $40(458)$ & 33 (249) & \\
\hline Secondary & $51(594)$ & 55 (413) & \\
\hline More than secondary & $4(45)$ & $6(46)$ & \\
\hline \multicolumn{4}{|l|}{ Wealth index } \\
\hline Lower & $41(477)$ & 39 (294) & \\
\hline Middle & 19 (225) & $21(157)$ & 0.608 \\
\hline Higher & $40(463)$ & $40(304)$ & \\
\hline \multicolumn{4}{|l|}{ Residence } \\
\hline Urban & $28(320)$ & $22(165)$ & 0.005 \\
\hline Rural & $72(843)$ & 78 (590) & \\
\hline \multicolumn{4}{|c|}{ Comprehensive HI V Knowledge } \\
\hline No & $51(596)$ & $51(384)$ & 0.913 \\
\hline Yes & $49(570)$ & 49 (371) & \\
\hline
\end{tabular}

May not add to total due to missing data. 
Appendix 5. Levels of key indicators at baseline and midline in four COMPACT communities for males and females

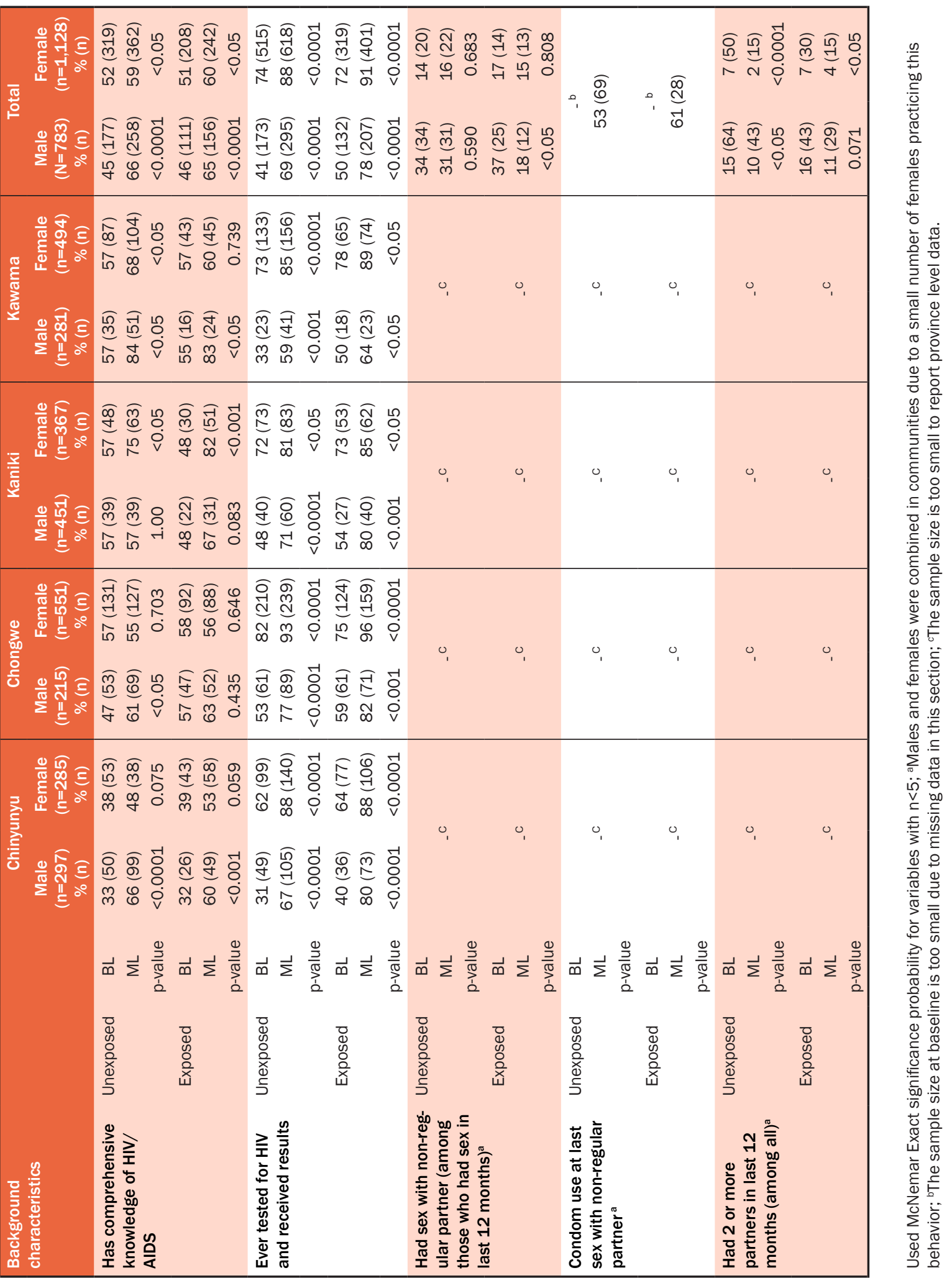


Appendix 5. Levels of key indicators at baseline and midline in four COMPACT communities for males and females (Con't)

\begin{tabular}{|c|c|c|c|c|c|c|c|c|}
\hline 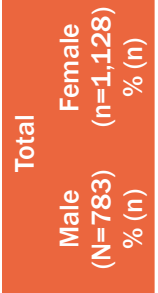 & 总 & 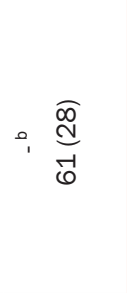 & 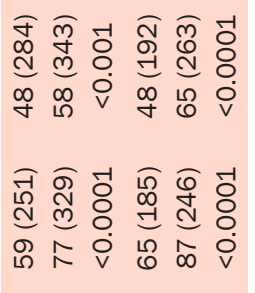 & 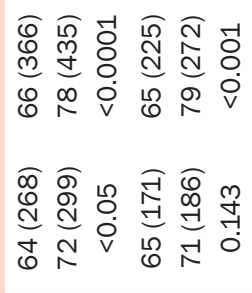 & 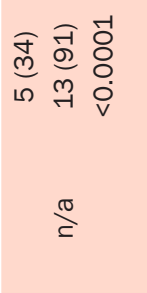 & 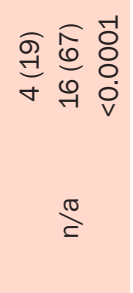 & 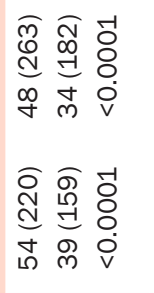 & 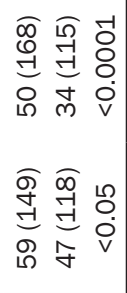 \\
\hline 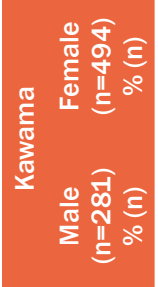 & $u_{1}$ & $0_{1}$ & 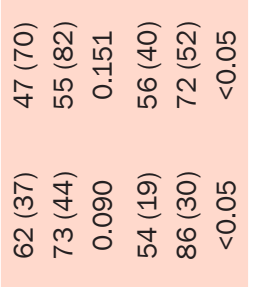 & 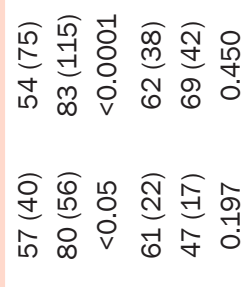 & 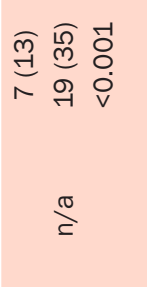 & 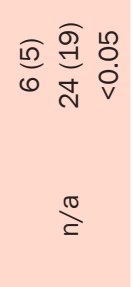 & 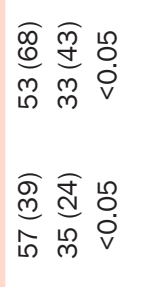 & 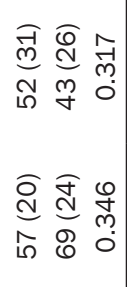 \\
\hline 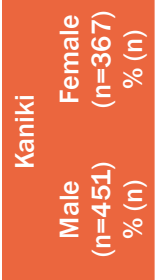 & $u_{1}$ & $u_{1}$ & 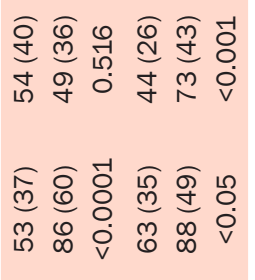 & 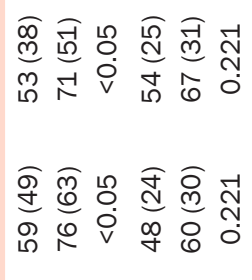 & 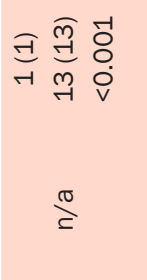 & 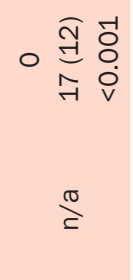 & 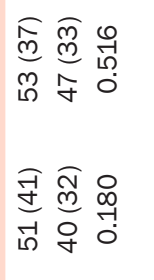 & 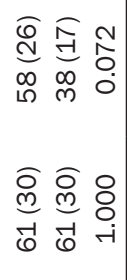 \\
\hline 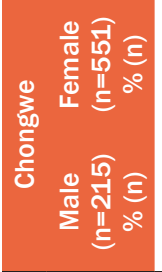 & $u_{1}$ & $u_{1}$ & 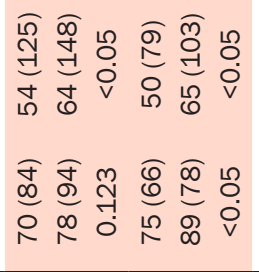 & 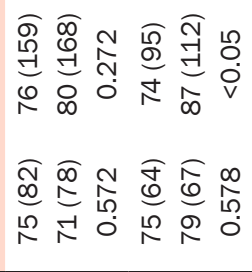 & 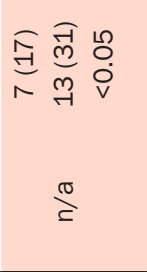 & 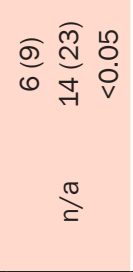 & 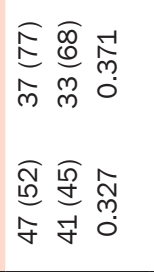 & 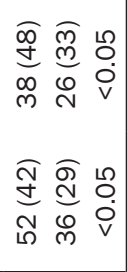 \\
\hline 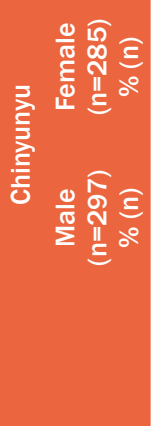 & 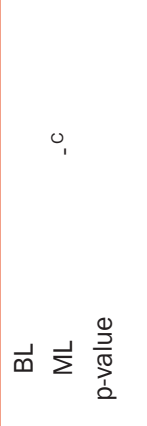 & $\vec{\omega} \vec{\Sigma} \frac{\frac{0}{m}}{\frac{m}{d}}$ & 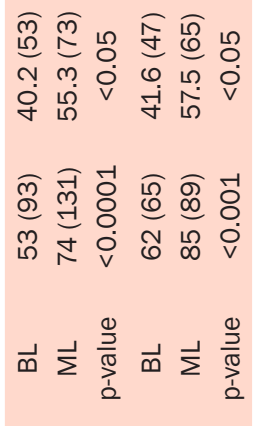 & 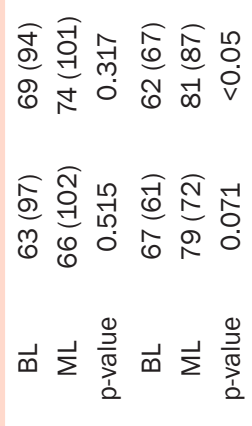 & 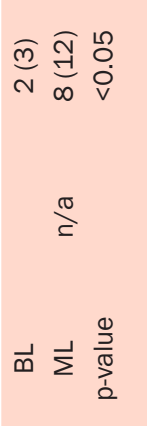 & 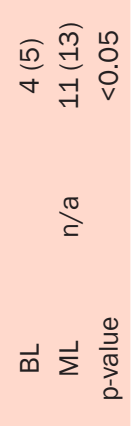 & 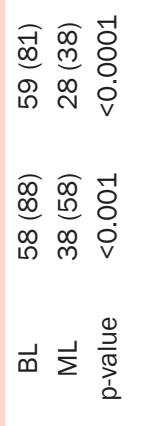 & 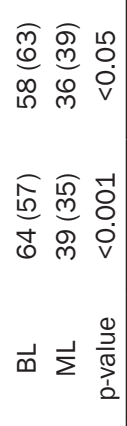 \\
\hline 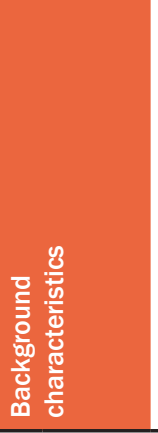 & 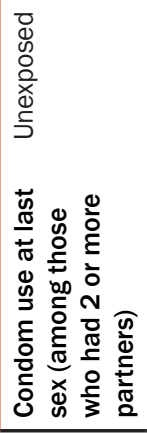 & 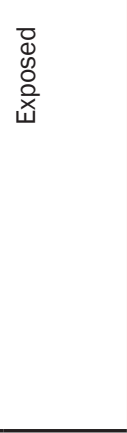 & 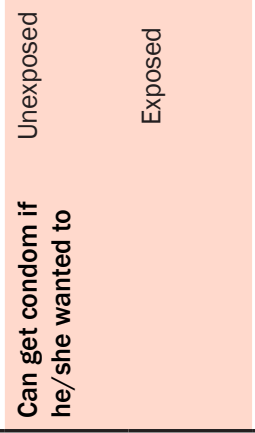 & 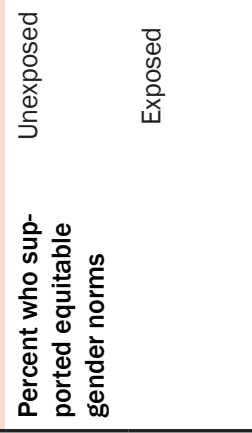 & 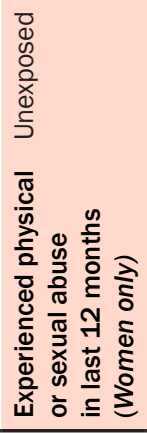 & 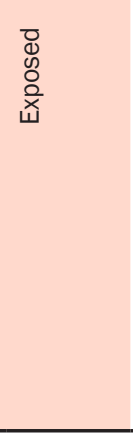 & 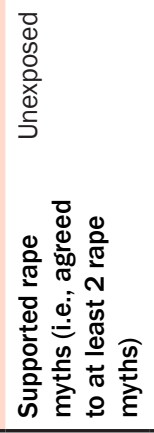 & $\begin{array}{l}\overline{0} \\
0 \\
0 \\
0 \\
\dot{x} \\
\text { w }\end{array}$ \\
\hline
\end{tabular}




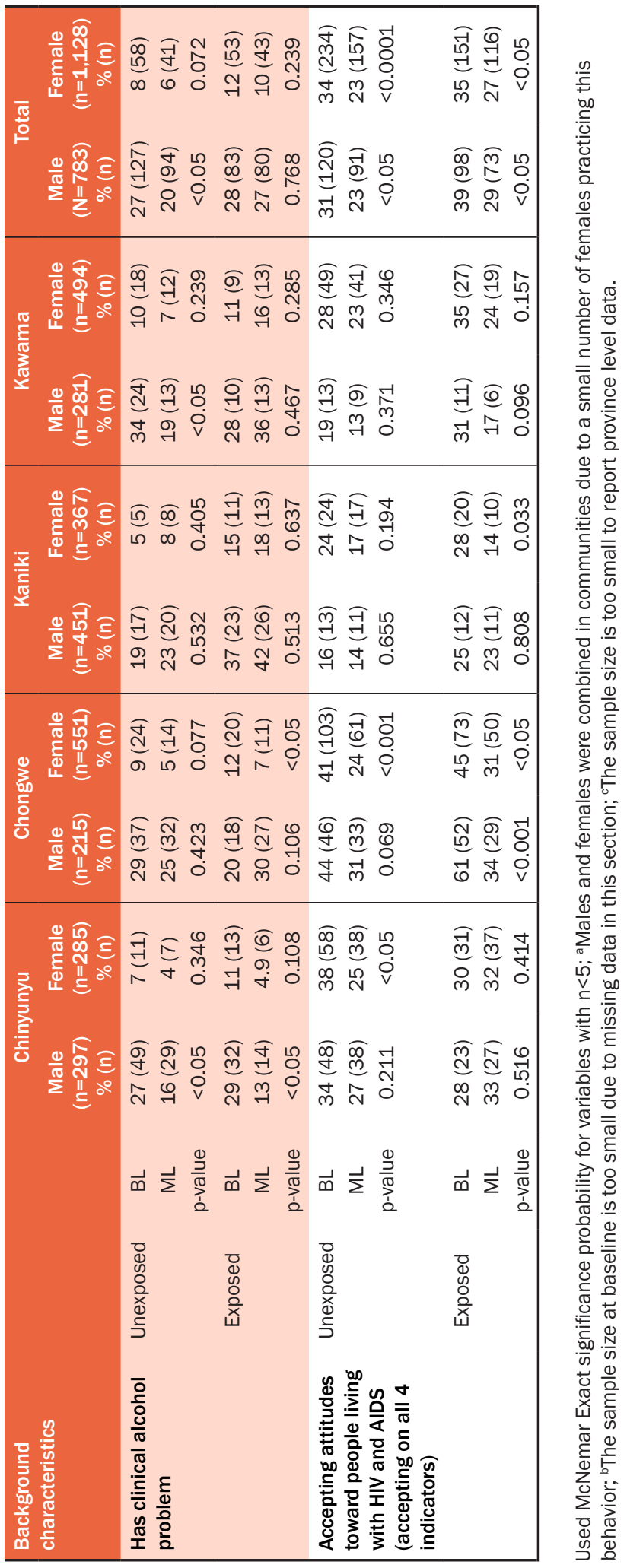


Appendix 6. Key indicators for adolescent boys and girls aged 15-19 years

\begin{tabular}{|c|c|c|c|c|}
\hline \multirow[t]{2}{*}{ Background characteristics } & & & \multicolumn{2}{|c|}{ Total } \\
\hline & & & $\begin{array}{c}\text { Male } \\
(\mathrm{N}=229) \\
\%\end{array}$ & $\begin{array}{c}\text { Female } \\
(n=301) \\
\%\end{array}$ \\
\hline \multirow[t]{6}{*}{ Had sex in the last 12 months } & Unexposed & $B L$ & $28(36)$ & $43(77)$ \\
\hline & & ML & $29(35)$ & $42(77)$ \\
\hline & & p-value & 0.882 & 1.0 \\
\hline & Exposed & $\mathrm{BL}$ & $22(13)$ & $29(31)$ \\
\hline & & $\mathrm{ML}$ & $38(23)$ & $32(34)$ \\
\hline & & p-value & 0.201 & 0.414 \\
\hline \multirow[t]{6}{*}{ Heard of ways to avoid pregnancy } & Unexposed & $\mathrm{BL}$ & & 39 (71) \\
\hline & & ML & $\mathrm{n} / \mathrm{a}$ & $66(121)$ \\
\hline & & p-value & & $<0.0001$ \\
\hline & Exposed & $\mathrm{BL}$ & & $40(44)$ \\
\hline & & ML & $\mathrm{n} / \mathrm{a}$ & $83(90)$ \\
\hline & & p-value & & $<0.0001$ \\
\hline \multirow{6}{*}{$\begin{array}{l}\text { Currently using method to avoid/delay } \\
\text { pregnancy among those who had sex } \\
\text { in last } 12 \text { months }\end{array}$} & Unexposed & $\mathrm{BL}$ & & $11(13)$ \\
\hline & & ML & & $32(39)$ \\
\hline & & p-value & & $<0.001$ \\
\hline & Exposed & $\mathrm{BL}$ & & $9(8)$ \\
\hline & & ML & & $26(24)$ \\
\hline & & p-value & & $<0.05$ \\
\hline \multirow[t]{6}{*}{ Unintended pregnancy (at last birth) } & Unexposed & $\mathrm{BL}$ & & $59(24)$ \\
\hline & & ML & & $66(27)$ \\
\hline & & p-value & & 0.513 \\
\hline & Exposed & $\mathrm{BL}$ & & $75(15)$ \\
\hline & & ML & & $80(16)$ \\
\hline & & p-value & & 0.706 \\
\hline
\end{tabular}

Used McNemar Exact significance probability for variables with $n<5$. 
30 - The Community Mobilization for Preventive Action (COMPACT) Project in Zambia 

Population Council/Zambia

P/Bag RW 319, Lusaka, 10101

Plot 4108, Mwinilunga Road,

Sunningdale, Kabulonga

Lusaka, Zambia

www.popcouncil.org 